\title{
From northern Italian to Asian wh-in situ: A theory of low focus movement
}

\author{
Caterina Bonan \\ University of Cambridge \\ cb2098@cam.ac.uk
}

Received: 06-01-2021

Accepted: 01-03-2021

Published: 23-03-2021

How to cite: Bonan, Caterina. 2021. From northern Italian to Asian wh-in situ: A theory of low focus movement. Isogloss: Open Journal of Romance Linguistics 7, 4: 1-59.

DOI: https://doi.org/10.5565/rev/isogloss.108

\section{Abstract}

The mainstream literature on the Romance dialects of northern Italy has explained the morphosyntax of clause-internal wh-elements in answer-seeking interrogatives as either the result of interrogative movement into the lower portion of the high left periphery (Munaro et al. 2001, Poletto \& Pollock 2015, a.o.), or as a canonical instance of scope construal (Manzini \& Savoia 2005;2011). New empirical evidence from Romance suggests that there is more at stake in the computation of wh-interrogatives than we used to think, and that neither of the existing approaches to northern Italian 'wh-in situ' can be maintained. Here, I argue that northern Italian dialects and Asian languages are, at least in this respect, more similar than we originally thought, and then I offer a new, derivationally economic and cross-linguistically supported understanding of the morphosyntax of northern Italian wh-in situ: the theory of WH-TO-FOC. Accordingly, all cross-linguistic core properties of this phenomenon can be attributed to different combinations of the setting of universal micro-parameters related to the interrogative movement of wh-elements.

Keywords: wh-movement; focus; Q-particles; wh-in situ; peripheries; language change. 


\section{Table of Contents}

\section{Introduction and overview}

2. Low movement of wh-elements and the focus/wh- parallel

3. From the Grammar of $\mathrm{Q}$ to the theory of WH-TO-FOC

\author{
4. The theory of WH-TO-FOC \\ 5. A new theory of Northern Italian \\ wh-in situ \\ 6. Conclusions \\ References
}

\section{Introduction and overview*}

In the last two decades, the literature on the Romance dialects of northern Italy (for short, northern Italian dialects, NIDs) has explained the morphosyntax of clauseinternal wh-elements in answer-seeking interrogatives as either the result of interrogative movement into the lower portion of the high left periphery (HLP) (Munaro et al. 2001, Poletto \& Pollock 2015, a.o.), or as a canonical instance of scope construal (Manzini \& Savoia 2005;2011). However, novel data from Romance challenge both existing analyses, which I shall henceforth refer to as the 'remnant-IP movement analysis' and the 'covert movement analysis', and encourage the pursuit of a different, hitherto virtually unexplored path that I will guide the reader through in what follows. To do so, I shall make extensive use of a number of interesting phenomena related to the interrogative use of wh-elements in a variety of Venetan spoken in the Provincia di Treviso, and of substantial Lombard and Venetan data presented in Manzini \& Savoia (2005). ${ }^{\dagger}$

Importantly, the existence of influential pieces of research that understand northern Italian wh-in situ as an instance of masked interrogative movement targeting the HLP, as in the 'remnant-IP movement analysis', has led numerous scholars to the conclusion that the phenomenon of northern Italian wh-in situ is of a diametrically opposed type with respect to Asian wh-in situ. My main aim here will be to show that this does not hold true for the variety of eastern Trevisan under investigation: throughout, I will argue for an alternative analysis that I then extend to other NIDs in $\$ 5$. My claim is that northern Italian and Asian wh-in situ are actually much more similar than we used to think.

This work was supported by the Swiss National Science Foundation, project \#P2GEP1_184384, which I gratefully acknowledge. I am indebted to Ur Shlonsky and Giuliano Bocci, without whom none of this would have been possible, and to my doctoral committee for many a precious insight: Adriana Belletti, Cecilia Poletto, Adam Ledgeway and Guglielmo Cinque. My gratefulness also goes to Fuzhen Si, Victor Pan, and Luigi Rizzi for their invaluable comments, my anonymous reviewers, my proof-reader Jamie Douglas, and my colleagues Lucas Tual and Giuseppe Samo. All remaining errors are my own.

$\dagger \quad$ The variety of Venetan analysed in this article (henceforth, 'eastern Trevisan') is the one described in Bonan (2021), i.e., a rural variety spoken in the the wider Ponte di Piave area. The data presented in my monograph and here were gathered first from my own native intuitions, then checked using two on-line questionnaires that asked for Likert-scale evaluations, and refined over the course of multiple sessions involving one-to-one grammaticality judgements on the most complex structures. My informants, twenty-two in total, all live in the wider Ponte di Piave area; they all have been exposed to Trevisan since birth and use the language daily. 
The notion of wh-in situ, used to refer to wh-elements that surface clauseinternally at Spell-Out, was made famous by Huang's (1982) influential work on the interrogatives of Chinese Mandarin and has animated much literature on formal grammar since. According to Huang, the choice between wh-ex situ and wh-in situ is parametrised and follows from a language-specific choice between overt and covert wh-fronting, respectively. This understanding was mainly based on the observation that, as Cheng (2009: 767) formulates it, "one of the most fascinating aspects of wh-in-situ is that the in-situ wh-items, though in-situ, can take wide scope, on a par with moved wh-items". Several subsequent investigations supported Huang's claim, although it has recently become clear that there are at least three broad problems with this proposal. First, despite being subject to the same interpretative scope as their moved counterparts, clause-internal wh-elements and overtly fronted wh-elements are now acknowledged to have different constraints in terms of sensitivity to islands and intervention effects: the difficulty of dealing with these challenges in the framework of a simple 'interpretation vs surface structure' phrasal-movement parameter has eventually led researchers to pursue alternative means to capture the differences between wh-in situ and total fronting into the HLP (see Cheng 2003 for a survey). A second problem posed by Huang's generalisation is that so-called wh-in situ languages like Chinese do not completely circumvent the option of total fronting in answer-seeking interrogatives (Tang 1988, Wu 1999, Cheung 2008;2014, Pan 2014, a.o.), while wh-fronting languages such as Standard English do make use of the wh-in situ strategy in certain contexts. Accordingly, English cannot be said to manifest the negative setting of the 'interpretation vs surface structure' movement parameter, since wh-in situ is not only possible but in limited cases also compulsory in answer-seeking questions, notably in multiple whquestions (Kuno \& Robinson 1972, Pesetsky 2000, Kotek 2016, Kotek \& Erlewine 2016, a.o.). A third problem with Huang's approach is the observation that, in a non-negligible number of languages what looks like wh-in situ is actually an instance of low movement of the wh-element. I discuss this in what follows.

\subsection{Types of wh-in situ}

It is commonly assumed that, in answer-seeking interrogatives, the phenomenon of wh-in situ comprises two major types. ${ }^{1}$ The first type, usually referred to as 'pure' wh-in situ, encompasses a variety of languages in which the wh-element surfaces clause-internally, i.e., in its external-merge position, while total wh-fronting is generally excluded, as in the Chinese example in (1): ${ }^{2}$

(1) a. Ni kanjian-le SHEI?

(Mandarin Chinese)

$$
\begin{aligned}
& \text { you see-ASP who } \\
& \text { 'WHO did you see?' }
\end{aligned}
$$

b. * SHEI $_{\mathrm{i}}$ ni kanjian-le __i ?

1 It is important to note that throughout, I use the label 'wh-in situ' to refer to whelements that surface clause-internally, regardless of whether these are literally in situ, i.e., in their external-merge site, or in a derived position.

2 In the examples and in the English translations, I use SMALL CAPS for focused constituents (wh-elements in interrogatives and foci). Conversely, the use of SMALL CAPS in glosses is purely stylistic. 
who you see-ASP

(Huang 1982: 253(159))

Languages of this type include Chinese (Huang 1982, Soh 2005, Huang \& Li 2009, Jin 2014, a.o.), Japanese (Hagstrom 1998, Kishimoto 2005, a.o.), Korean (Beck \& Kim 1997), and Sinhala (Kishimoto 2005, Slade 2011, a.o.). ${ }^{3}$

A second type of wh-in situ is the so-called 'optional' type. Optional wh-in situ is a widespread phenomenon in Romance that includes languages in which the option of fronting the wh-element into the HLP co-exists rather peacefully with the possibility of stranding it clause-internally. Languages of this type comprise French (Baunaz 2005, Mathieu 2009, Shlonsky 2012, Faure \& Palasis 2021, a.o.), Brazilian (Kato 2013, Figueiredo Silva \& Grolla 2016, Rosemeyer 2019, a.o.) and European Portuguese (Cheng \& Rooryck 2000, Kaiser \& Quaglia 2015, a.o.), Spanish (UribeEtxebarria 2002, Etxepare \& Uribe-Etxebarria 2005, Reglero 2015, Biezma 2018, a.o.), and NIDs (Munaro 1999, Poletto 2000, Manzini \& Savoia 2005, Manzini 2014, Bonan 2021, a.o.). An example of alternation between total fronting into the HLP and real wh-in situ is given in (2):

a. QUI t'as wu _i ?
who you=have seen
'WHO did you see?'
b. T'as vu QUI?
you=have seen who

(French)

It is worth noting that the idea of 'optionality' in the placement of wh-elements in their interrogative use has animated a non-negligible amount of literature on Romance interrogatives. To my understanding, the co-existence of semantically equivalent syntactic strategies functions as an indicator of an intermediate diachronic stage. Accordingly, like in all intermediate stages, alternations like that in (2) will eventually become impossible, leading to the generalisation of one or the other strategy, or to a pragmatic/sociolinguistic specialisation of each: the current trend in the literature is indeed against free alternation (Baunaz 2005, Pires \& Taylor 2009, Roussou et al. 2014, Biezma 2018, Vlachos \& Chiou 2020, Faure \& Palasis 2021, a.o.). Linguistic stages characterised by optionality are widely acknowledged in both historical and synchronic linguistics, thus their existence is far from being troublesome. Outside of the Romance domain, what has been described as a mixed picture of wh-movement and wh-scoping (and everything in between) is in fact quite common, possibly even more than in Romance, and has been accounted for without considering it a theoretical issue: the scoping strategies observed in natural languages are often not homogeneous, both across closely related languages and language-internally (Wahba 1999, Kahnemuyipour 2001, Cole \& Hermon 1994;1998, a.o.). I shall therefore not join this discussion here, and rather focus on more substantial theoretical matters.

3 Wh-fronting into the HLP is by no means the default interrogative strategy in Chinese: its classification as a pure in situ language can therefore be maintained for descriptive purposes. 
With this in mind, it is important to also acknowledge the existence of a third type of wh-in situ languages, namely one in which the clause-internal whelement surfaces low in the phonetic string, yet not in the external-merge position. These orderings are a by-product of a low interrogative movement that has in turn been analysed as either targeting the Spec of $v \mathrm{P}$ or that of Belletti's (2004) Foc, in the low left periphery (LLP). ${ }^{4}$ Surprisingly, this cross-linguistically robust phenomenon has gone almost unnoticed in the literature on Romance. The languages that display low interrogative movement can be either of the pure type (Old Japanese in the Nara period as in Watanabe 2003, Aldridge 2009; Archaic Chinese as in Aldridge 2010, etc.) or of the optional type (Old Japanese in the Heian period as in Watanabe 2003; Persian as in Kahnemuyipour 2001, Karimi \& Taleghani 2007; Malayalam as in Jayaseelan 1996; Hindi-Urdu as in Mahajan 1990, Manetta 2010, Dayal 2017; Aghem as in Hyman 2005, Aboh 2007; Brazilian Portuguese as in Kato 2013; Trevisan as in Bonan 2021, etc.).

An example of a language with clause-internal interrogative movement is eastern Trevisan, a Venetan dialect in which total fronting into the HLP, as in (3a), coexists with fronting into the LLP, as in $(3 \mathrm{~b}):^{5}$
a. $\quad \mathrm{KI}_{\mathrm{i}}$ ghe gatu dato $\mathrm{i}$ pomi _i ? to who 3.DAT have=you given the apples 'TO WHOM did you give the apples?'
b. ghe gatu dato $\mathrm{A} \mathrm{KI}_{\mathrm{i}} \mathrm{i}$ pomi _i ? 3.DAT have=you given to who the apples

The option of real wh-in situ, unavailable in answer-seeking interrogatives, as in (4a), is the norm in the echo questions of eastern Trevisan, in which the use of interrogative syntax is excluded. This is illustrated by the absence of subject-clitic inversion (SCLI) in (4b): ${ }^{6}$
a. * ghe
gatu
dato
i
pomi
A KI?
3.DAT have=you given the apples to who
'TO WHOM did you give the apples?'
b. te ghe gà dato $\mathrm{i}$ pomi $\mathrm{A}$ KI?!
you $=3$.DAT have given the apples to who
'You gave the apples TO WHOM?!'

The strategy of real wh-in situ seen in the echo question in (4b) is also available in many fronting languages in special questions asking for repetitions and/or clarifications, and in multiple-wh interrogatives, i.e., questions that bear on more than one constituent. Nonetheless, only the morphosyntax of answer-seeking

\footnotetext{
$4 \quad$ I use 'LLP' for the periphery of $v \mathrm{P}$, following Poletto (2006) and Giorgi (2016).

5 The DO ' $\mathrm{i}$ pomi' in ( $3 \mathrm{~b}$ ) is neither right-dislocated nor marginalised (refer to §2).

6 In the answer-seeking interrogatives of this variety (wh- and polar), SCLI is the most frequently used question-formation strategy; 'doubly-filled COMP' structures are also available to some speakers (a ki ke te ghe ga dato i pomi? 'Lit: To whom that you gave the apples?'), while the absence of SCLI is not.
} 
single-wh interrogatives will be taken into consideration here, leaving the investigation of all other types of wh-in situ for further work.

In Bonan (2021), I claimed that instances of low movement such as the one in (3b) are driven by a syntactically active [focus]-feature in the LLP. From this low movement, it follows that the phenomenon of 'wh-in situ' in the answer-seeking interrogatives of NIDs can be neither movement into the low portion of the HLP, nor a mere instance of interrogative movement delayed until LF. In the rest of the paper, I outline an understanding of the phenomenon of wh-in situ that accounts both for the low movement in (3b), and for its absence in some varieties.

\subsection{Main characters and central claims}

Cable (2010) provided extensive evidence in favour of the claim that, for numerous phenomena surrounding wh-operators, the locus of explanation does not lie in the wh-operators themselves, as in the common consensus, but rather in a distinct element that bears a special semantic and/or syntactic relationship to the whoperator: the so-called Q-particle. Accordingly, the answer-seeking questions of all languages have Q-particles, not only those in which these are phonetically realised, and vary minimally along two variables. The first variable is whether their Qparticle 'projects', i.e., selects the wh-element and drags it along when attracted into the HLP, or 'adjoins', i.e., it moves into the HLP alone, leaving the wh-element stranded clause-internally. Then, a second variable concerns the parametrised choice between overt and covert interrogative movement.

In Bonan (2021), I claimed that instances of eastern Trevisan 'wh-in situ' such as that in (3b) involve the presence of a silent Q-particle that adjoins to the whelement, and are best characterised as a consequence of focus-movement of the whelement into Belletti's (2004) Foc, in the LLP. Belletti indeed posited the existence of a periphery above $v \mathrm{P}$ composed of a focal projection surrounded by two topic projections, along the lines of the diagram in (5). Here, only the role of Foc, and partially that of the lowest topic projection, will be dealt with.

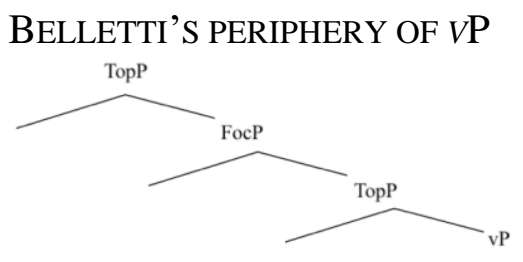

In Bonan (2021b), I proposed an explanation for the different distributional properties of wh-elements and contrastive foci in eastern Trevisan and Standard Italian in terms of a parametrisation of the structural loci in which the features relevant to interrogative wh-movement, $[\mathrm{Q}]$ and [foc], are realised: scattered between the LLP and the HLP in eastern Trevisan, bundled in the HLP in Italian. I then claimed that the variation attested cross-linguistically in answer-seeking interrogatives can be understood as a combination of the above parameters, which are powerful enough to account not only for the synchronic state, but also for the diachronic evolution, of wh-in situ languages (\$4). On the basis of my investigation of the interrogative syntax of eastern Trevisan, I have then claimed that a crosslinguistic reconsideration of the role of the LLP in the derivation of 'wh-in situ' is in order. 
Here, I provide an overview of my analysis of eastern Trevisan wh-in situ, then show how this further applies to the interrogative syntax of all NIDs and to the diachrony of Japanese and Chinese. I thus offer a derivationally economical and cross-linguistically valid explanation to the phenomenon of northern Italian in situ as a whole, which I treat as an instance of present-day Chinese/Japanese wh-in situ plus, in some cases, an additional low movement of the clause-internal wh-element. Consequently, I will argue that those wh-in situ languages that encode [focus] in the LLP encompass at least three sub-types: one in which low focus agreement is followed by movement, one in which AGREE alone is enough, and mixed systems.

\section{Low movement of wh-elements and the focus/wh- parallel}

In this section, I summarise the main motivations for saying that there is low movement of wh-elements in eastern Trevisan. Evidence comes from constituent order, the binding properties of both clause-internal wh-elements and the material that follows them, and the parallel morphosyntactic properties of clause-internal foci. I also maintain that adverb-placement tests support the claim that the targeted position is located in the LLP.

In Bonan (2021;2021b), I argued that the surface position of clause-internal wh-elements such as the one in (3b), repeated here in (6), is an internal-merge one. Accordingly, the marked order IO $>$ DO is derived by moving the wh-element to a clause-medial position.

ghe ga-tu dato A $\mathrm{KI}_{\mathrm{i}} \mathrm{i}$ pomi _i ?
3.DAT have=you given to who the apples
'TO WHOM did you give the apples?'

My claim followed mainly from the observation that IO>DO is not the base order of eastern Trevisan: the unmarked order of out-of-the-blue declaratives is indeed SVO, with the IO that follows the DO in ditransitive constructions, as in (7). ${ }^{7}$
a. ghe go dato i pomido a dzaniIo
3DAT have 1 Ps given the apples to John
'I gave the apples to John'
b. * ghe go dato a dzaniIo i pomido
3.DAT have 1 PS given to John the apples

Preposing the IO to the DO, as in (7b), is not felicitous. Adverbials, when present, need to follow all theta-elements. The natural order for adverbials is TIME>PLACE, as illustrated in (8a): while PLACE>TIME is marginal, as in (8b), any order in which an adverbial precedes the DO is excluded, as in $(8 \mathrm{c})$ :
(8)

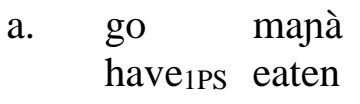
noki
SeraTime
aa sagraplace
gnocchi yesterday night
at.the festival 


\section{b. ? go manà joki Do aa sagraplace jeri seratime have 1 PS eaten gnocchi at.the festival yesterday night \\ c. * go manà $\{$ jeri seratime $\} \quad\{$ aa sagraplace $\}$ jokido have $_{1 \mathrm{PS}}$ eaten yesterdaynight at.the festival gnocchi} 'I ate gnocchi yesterday evening at the festival'

The declarative linear ordering in (7) and (8) is however not reproduced when an answer-seeking question bears on the IO of a ditransitive verb, or on an adverbial. In such cases, the natural orders are those in which the IO precedes the DO, as in (9), and adverbials precede internal arguments, as in (10):

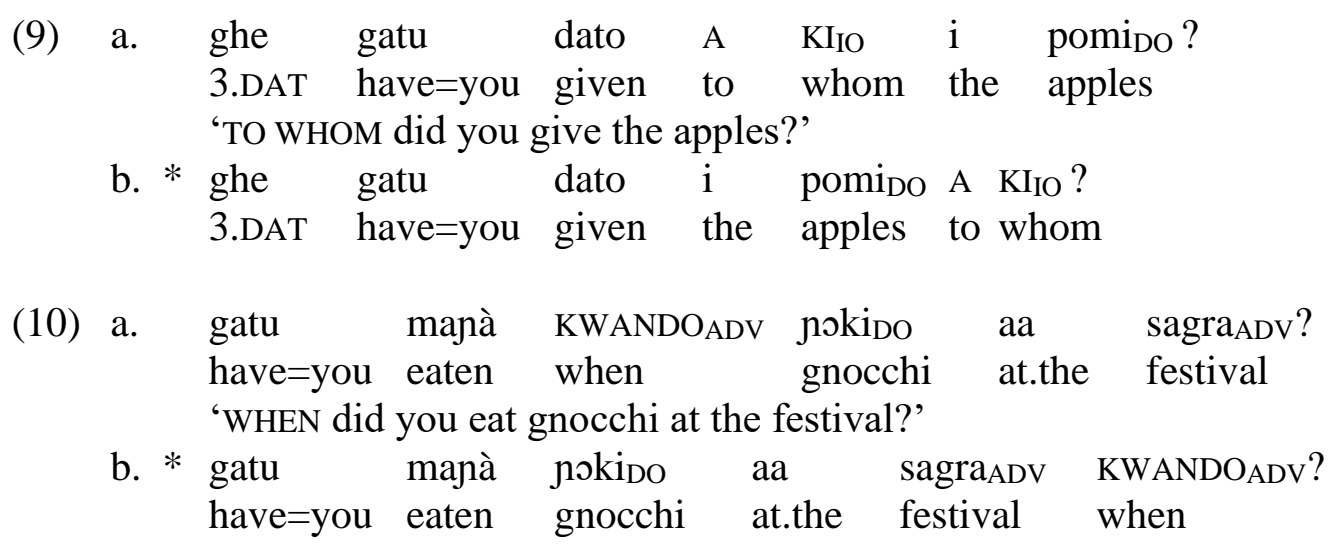

Given (9) and (10), I posited that eastern Trevisan clause-internal wh-elements move out of their external-merge position, to a low functional projection outside of $\nu \mathrm{P}$ (refer to $\S 2.1$ for a characterisation).

Among the reasons behind my claim that the orders in (9) and (10) are derived via movement of the wh-element, rather than rightward movement of what follows the wh-element linearly, is the observation of instances like (11), which show that there is no PF constraint that disallows wh-elements to occupy the main stress position in eastern Trevisan. ${ }^{8}$

(11) gatu visto KI?
have=you seen who
'WHO did you meet?'

Additionally, dislocated constituents are required to be phrased as independent intonational phrases in this variety, with obligatory realisation of a clitic co-indexed with the dislocated element (when available), plus GENDER and NUMBER agreement on the past participle. Observe the right-dislocation in (12):
(12) ghe $\mathbf{i}_{\mathrm{j}}$ gatu dati $\mathrm{A}$ KI, $\mathrm{i}$ pomi $\mathrm{j}_{\mathrm{j}}$ ?

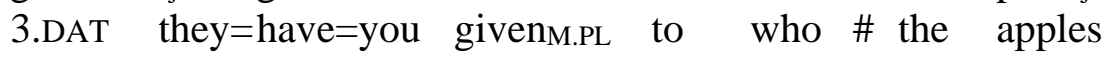
'The apples, TO WHOM did you give?'
(Lit: 'Did you give them TO WHOM, the apples?')


In the absence of any of the above properties (independent intonation, co-indexed clitic, past participle agreement), dislocations fail. Observe also the additional evidence in (13), where the in situ constituents that follow the displaced wh-element can only appear in their base order, while any relative order is possible when these are right-dislocated, as illustrated in (14):
a. * ghe
ga-tu
regaeà
KWANDO
aa
marìa 1 ancl?
3.DAT have=you gifted
when
to.the
Mary
b. ghe
ga-tu regaeà
KWANDO
lanel aa
the ring
3.DAT have $=$ you gifted when
'WHEN did you give Mary the ring?'
a. ghe oj $_{\mathrm{j}}$ ga-tu
regaeà
KWANDO, aa
marìa, 1 ancl $\mathrm{j}_{\mathrm{j}}$ ?
3.DAT $=\mathrm{it}=$ have $=$ you gifted when \# to.the Mary the ring
b. ghe $\mathbf{o}_{\mathrm{j}}$ ga-tu regaeà KWANDO, lancl $\mathrm{j}_{\mathrm{j}}$ aa marìa? 3.DAT it= have=you gifted when \# the.ring \# to.the Mary
'The ring, WHEN did you give to Mary?'

Authors such as Cardinaletti (2002) and Samek-Lodovici (2015) have argued that the clause-internal focused constituents of Italian are stressed in situ, with all following material destressed either in situ or ex situ. In case the post-focal material lies in situ, this is understood as 'marginalised', and it displays canonical binding properties. Conversely, when the post-focal constituents are non-clitic right-dislocated, all binding relations requiring c-command are excluded. In this respect, note that in eastern Trevisan, the unfelicitous IO $>$ DO and ADV $>$ DO orders in the declaratives in (7) and (8) become possible in case of contrastive focalisation of the first element of the pair. This is illustrated in (15):
a. ghe go dato A dzANI $\mathrm{i}$ pomi!
3.DAT have 1 PS given to John the apples
'It's TO JOHN that I gave the apples' (Lit: 'I gave TO JOHN the apples')
b. go manà JERI SERA noki!
have $_{1 P S}$ eaten yesterday night gnocchi
'It's YESTERDAY NIGHT I ate gnocchi'
(Lit: 'I ate YESTERDAY NIGHT gnocchi')

However, the existence of marked orders such as those in (15) does not imply that the post-wh material of interrogatives can actually be understood as marginalised or non-clitic right dislocated, as witnessed by the binding relations in (16): ${ }^{9}$

(16) dzani $\mathrm{l}_{\mathrm{i}}$ ghe gà domandà $\mathrm{AL} \quad \mathrm{B} \mathrm{D}^{\prime} \mathrm{A}_{\mathrm{j}}$ el $\mathrm{so}_{\mathrm{i} /} /{ }^{\mathrm{j}}$ putinot John =he 3.DAT has asked to.the boy the his doll 'John asked his doll TO THE BOY' (Lit: 'John asked TO THE BOY his doll')

$9 \quad$ Note that for the lexical subject in (16) to be construed with the corresponding nominative clitic does not mean that we are dealing with a topicalisation: eastern Trevisan lexical subjects systematically require clitic doubling (crucially, if dzani was topicalised, the full clitic pronoun $e l$ would be used, contrary to fact). 
That AL BDt'A ('to the boy') in (16) is not able to bind the DO el so putinst ('his doll') is an indicator that the former is in an internal-merge position: if it was in its external-merge site, it would have canonical binding properties, contrary to fact. ${ }^{10}$ Since that clause-internal foci surface in an external-merge position, the post-focal material in (15) and (16) cannot be marginalised in situ, in the sense of Cardinaletti and Samek-Lodovici: the type of marginalisation that they deal with only involves in situ foci. Additionally, for the subject in the canonical subject position in (16) to be able to bind the possessive determiner so ('his') in the post-focal DO, the DO must be c-commanded by the rest of the clause, excluding the possibility for it to be dislocated to the right. Conveniently, the binding relations observed in the declarative in (16) are replicated in interrogatives such as (17):

$$
\begin{aligned}
& \text { ghe ga-eo } \mathrm{i}_{\mathrm{i}} \quad \text { domandà } \mathrm{A} \quad \mathrm{KI}_{\mathrm{j}} \quad \text { el } \quad \mathrm{sO}_{\mathrm{i} /{ }^{\mathrm{j}}} \quad \text { putinot ? } \\
& \text { 3.DAT has=he asked to who the his doll } \\
& \text { 'TO WHOM did he ask his doll?' (Lit: 'Did he gift TO WHOM his doll?)' }
\end{aligned}
$$

Therefore, I maintain that the distribution of eastern Trevisan clauseinternal wh-elements is a by-product of the movement of the wh-element.

\subsection{Characterisation of the movement of clause-internal wh-elements}

Given the unmarked base-order discussed for Trevisan, and the observation that the clause-internal wh-elements of this variety move higher than $v \mathrm{P}$ yet not as high as the HLP, one might wonder why these surface below, rather than above, the linear position occupied by the active past participle, as in (18).

gatu manà KWANDO i pomi _i ?
have=you eaten when the apples
'WHEN did you eat the apples?'

The order observed in (18) follows straightforwardly from the claim that adverbials are not adjoined to $\nu \mathrm{P}$, but generated in the specifiers of rigidly ordered projections within the domain of the inflection, coupled to the observation that "(active) past participles must move to the head to the left of tutto ['all']" in Italian (Cinque 1999:46). This claim also stands in eastern Trevisan, as in (19) and (20): ${ }^{11}$

$$
\begin{array}{llll}
\text { a. } & \text { a ga } & \text { manà } & \text { tuto } \\
\text { she }= & \text { has } & \text { eaten } & \text { all }
\end{array}
$$

10 As a reviewer correctly points out, cross-over effects are expected with focus movement; nonetheless, this is a complex discussion that I wish to leave for further investigations. In passing, note that these observations also further support my claim that the Trevisan base order is DO>IO.

11 Trevisan 'tuto' can be a floating quantifier à la Sportiche (1988), as in (i)-(iv):

(i) ze finio [ tuto el pan ]

(ii) [ el pan $]_{i} 1$ ze finio [ tuto _ _ i ]

(iii) $[\text { el pan }]_{i} 1$ ze $\left[\text { tuto }{ }_{i}\right]_{j}$ finio

('is finished all the bread')

(iv) [ tuto el pan $]_{j} 1$ ze ${ }_{-j}$ finio _ ${ }_{j}$

('the bread 3PS is finished all')

('the bread 3PS is all finished')

('all the bread 3PS is finished')

However, it seems to me that at least in (19) the lack of a lexical restriction associated with tuto excludes the possibility to consider it a quantifier. 


$$
\begin{aligned}
& \text { b. * a ga tuto manà } \\
& \text { she= has all eaten } \\
& \text { 'She ate everything' }
\end{aligned}
$$

(20) a lo ga $\quad \underline{\text { manà }}$ tuto
she= it has
'She ate it all'

The eastern Trevisan past participle always surfaces higher than tuto, as evidenced by the ungrammaticality in (19b); note that the fact that tuto in (19a) is not necessarily the internal complement of manà ('to eat') is confirmed by (20), in which the adverbial reading is favoured by the presence of the clitic DO. ${ }^{12}$ Additionally, the same pattern is attested with ben ('well'), as in (21): ${ }^{13}$

$$
\begin{aligned}
& \text { a. a ga manà ben } \begin{array}{ll}
\text { (el pometo) } \\
\text { she= has eaten well the apple sauce } \\
\text { 'She ate (the apple sauce) well' }
\end{array} \\
& \text { b. * a ga ben majà (el pometo) } \\
& \text { she has well eaten the apple sauce }
\end{aligned}
$$

The cross-linguistic counterparts of 'all' and 'well' are acknowledged to lie in the functional portion known as the low adverbial space (LAS), whose upper border is commonly taken to be occupied by presuppositional negators such as Italian mica (Ledgeway \& Longobardi 2005). Orderings such as that in (22) thus suggest that the position targeted by the eastern Trevisan past participle is an aspectual projection located within the LAS, as illustrated in (23):

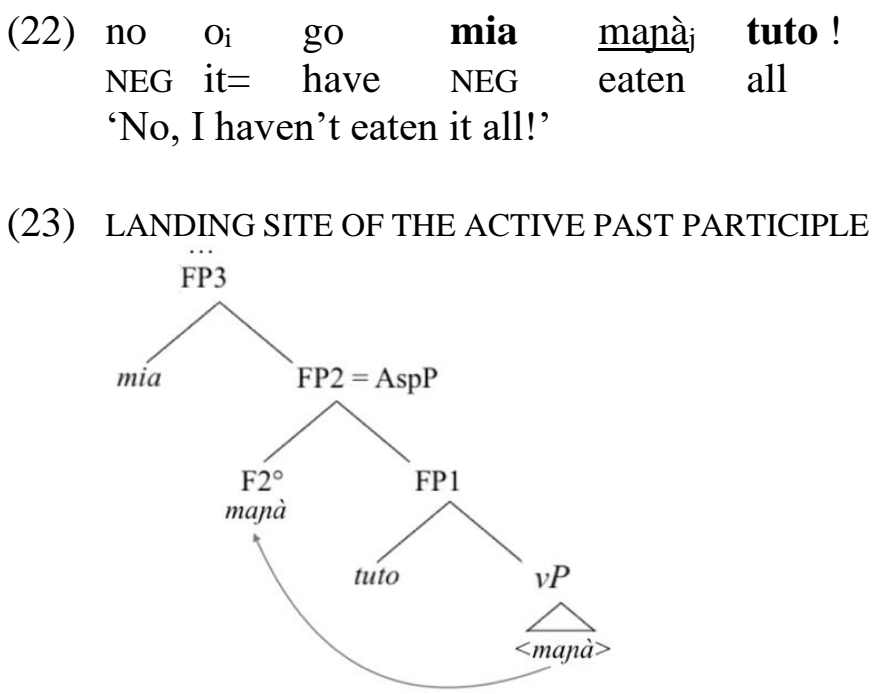

12 Also, the argumental use of tuto is technically not a problem for its status as an adverb, as a classification along these lines is compatible with a 'light predicate raising' analysis (see Cinque 1999, ch. 2 for a discussion).

13 A reviewer observes that someone could object that here ben doesn't mean 'well' in the regular sense, but 'really'; however, this is not the case here. 
An analysis along the lines of (23) is compatible with the claim that clause-internal wh-elements are internally-merged in the LLP, and with the 'PAST PARTICIPLE > WH $>$ DO' order of interrogatives. That the functional projection that hosts the clauseinternally moved wh-element is indeed lower than the LAS is made clear in (24):

o gatu $\underline{\underline{\text { manà }}} \begin{aligned} & \text { tuto/ben } \\ & \text { it= hWANDO? }\end{aligned}$
'WHEN did you eat it all/well?'well

We can therefore take eastern Trevisan to license instances of 'fake' wh-in situ, derived through a low movement which targets a projection within the LLP, along the lines of the diagram in (25):

\section{LANDING SITE OF CLAUSE-INTERNAL WH-ELEMENTS}

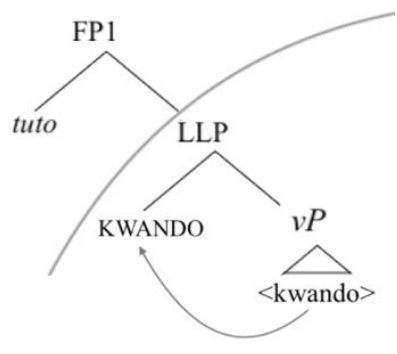

Cheng \& Bayer (2017: 21) describe South Asian wh-in situ as an instance of overt movement to the LLP, which makes these languages a "typologically interesting and significant type between full moving and in-situ languages". The variety of eastern Trevisan under consideration here clearly belongs to the same type.

\subsection{Clause-internally moved foci}

Clause-internal wh-elements targeting either Belletti's Foc or Spec $v \mathrm{P}$ have been argued for in numerous languages. A non-exhaustive list of works includes Jayaseelan (1996) for Malayalam; Turano (1998) for Albanian; Kahnemuyipour (2001) for Persian; Kato (2003;2013) for Brazilian Portuguese; Belletti (2006) for French; Hyman (1979;2005) and Aboh (2007) for Aghem; Aldridge (2009) for Old Japanese and then Aldridge (2010) for Archaic Chinese, Manetta (2010) \& Dayal (2017) for Hindi-Urdu; Manzini (2014) for NIDs; Poletto \& Pollock (2019) for NIDs, Badan \& Crocco (2021) for Italian.

My claim that the movement in (25) is driven by [focus] followed the observation that in eastern Trevisan, contrastive foci also surface clause-internally and naturally higher than their external-merge position, as in (26) and (27).

(26) a. A: so ke te ghe ga prestà el libro a Pjero know 1 Ps that you=3.DAT have lent the book to Piero 'I know that you lent the book to Piero'

b. B: ghe go prestà A TONI el libro __i, no a Pjero DAT have ${ }_{1 P S}$ lent to Toni the book NEG to Piero 'No, I lent the book TO TONI, not to Piero'

c. B': ? ghe go prestà el libro A TONI, no a Pjero DAT have $1_{1 P S}$ lent the book TO TONI NEG to Piero 


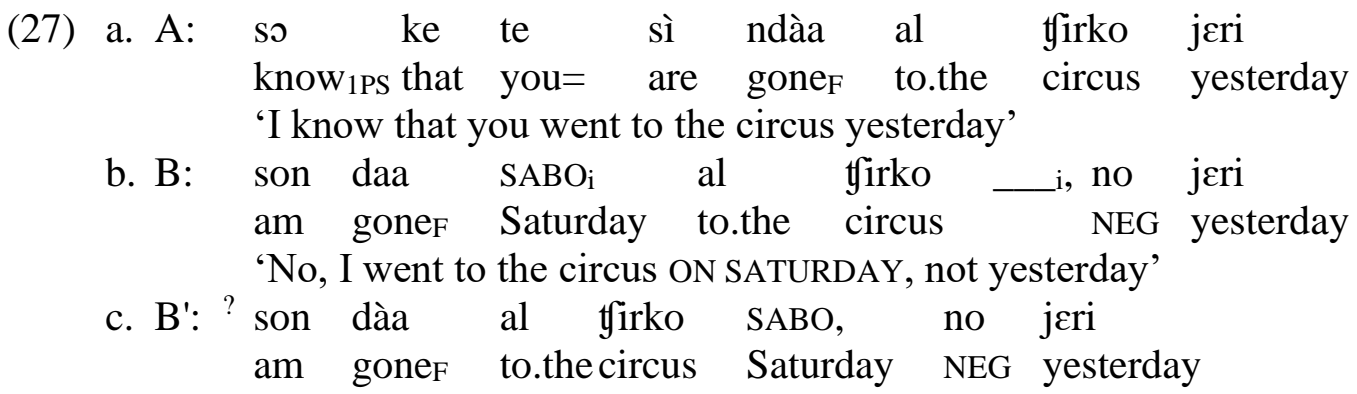

Orders such as those in (26b) and (27b) suggest that contrastive foci target a focal projection right below the one targeted by the past participle in eastern Trevisan, i.e., in the LLP, on a par with wh-elements. I posited that the targeted position is Belletti's Foc, along the lines of (28):

(28) CLAUSE-INTERNAL FOCUS MOVEMENT
a. [IP pro ghe
go [FP2 prestà [Foc
b. [IP pro son
A TPNIi $\quad[\mathrm{VP}$... el libro
$\left[\begin{array}{ll}\mathrm{i} & []]]\end{array}\right]$
$\mathrm{SABO}_{\mathrm{j}} \quad\left[\mathrm{VP} \ldots\right.$ al tgirko $\left.\left.\left.\_\mathrm{j} \quad\right]\right]\right]$

Although the movement optionality observed for contrastive foci in (26) and (27) could apparently threaten the parallel with wh-elements that I have pursued, it must be noticed that unmoved contrastive foci are never the natural option for eastern Trevisan speakers: they do not produce these orderings in elicitation tasks, and simply do not reject them when asked to provide grammaticality judgements. The possibility to have unmoved foci in eastern Trevisan should be understood as a contact phenomenon whereby the speakers are influenced in their judgements by standard Italian, which allows foci in situ. I thus maintain that the parallel between eastern Trevisan contrastive foci and clause-internal wh-elements is tenable.

Authors such as Horvath (1986) have claimed that whenever a language has at its disposal a specialised projection for contrastively-focused constituents, this projection is also available for wh-elements. An extension of the movement paradigm in (28) to the clause-internal wh-elements of eastern Trevisan thus comes straightforwardly, and appears well-justified semantically. It must nonetheless be noted that the interpretive similarity between contrastive foci and wh-elements, whereby both types of categories quantify over a contextually closed set, does not necessarily hold for non lexically-restricted wh-elements: only lexically-restricted wh-phrases are commonly understood to involve this type of quantification. What is more, that the feature responsible for movement of both wh-elements and foci is [focus] could technically be problematic in light of works such as É. Kiss (1998) and related, in which new information focus is claimed not to involve movement. However, eastern Trevisan foci do move, as I claim in what follows.

Belletti \& Rizzi (2017: 40) claim that in Italian, in the answer to a subjectquestion, the marked vs order is "overwelmingly preferred". This pattern is replicated in eastern Trevisan, as in (29):

$\begin{array}{ll}\text { a. Question: } & \text { KI ze ke ze rivà? } \\ & \text { who is that is arrived } \\ & \text { 'WHO's arrived?' }\end{array}$




\section{b. Answer: ze rivà d’̧ANI / UN TOZATO \\ is arrived John / a young.man \\ 'JOHN / A YOUNG MAN arrived' \\ (Lit: 'Arrived JOHN / A YOUNG MAN’)}

In a context in which, at the time of the event in (29), the speaker is unable to identify the person who enters the room while the interlocutor has the relevant information, the order in (29b) is attested with all verb classes and irrespective of the definite or indefinite nature of the post-verbal subject, both in Italian and in eastern Trevisan. Belletti \& Rizzi explain that the subject in VS orders such as those seen above expresses the value of the wh-variable, and is therefore "the carrier of the information asked for in the question", i.e., a focus of new information. Importantly, although in the answer in (29b) the verb is unaccusative, which might suggest that the observed order derives from the fact that the subject simply remains in situ, the authors argue that the same vs order with narrow focalisation of the subject is "also found with unergative and transitive verbs" (Belletti \& Rizzi 2017: 41). This pattern is also observed in eastern Trevisan, as illustrated in (30) and (31):
a. Question: KI ze ke ga stranudà?
who is that has sneezed
'WHO sneezed?'
b. Answer:

ga stranudà dJANI / UN TOZATO
has sneezed John / a
'JOHN / A YOUNG man sneezed'
(Lit: 'Sneezed JOHN / A YOUNG MAN')
a. Question: KI ze ke ga dzustà a makina? who is that has fixed the car 'WHO fixed the car?'
b. Answer: la ga dzustàa ḑANI / UN TOZATO
it $_{\mathrm{F}}$ has fixed $\mathrm{F}_{\mathrm{F}}$ John / a young.man
'JOHN / A YOUNG MAN fixed it'
(Lit: 'It fixed JOHN / A YOUNG MAN')

The uniform vs order for Italian subject focalisation is what led Belletti (2004) to postulate the presence of a low focus position in the LLP to which the subject of all verb classes is moved when it encodes the value of the wh-variable, i.e., in narrow focus environments. Further evidence in favour of this analysis comes from the word order observed in answers to wh-questions which bear on the IO of a ditransitive verb: while DO $>\mathrm{IO}$ is the base order of eastern Trevisan, as previously illustrated in (7a), the same order is not felicitous in an answer to a wh-question like (32), in which IO>DO is required, as in (32c):
a. Question:
A KI ghe gatu
dato i pomi? TO WHO 3.DAT have=you 2 PS given the apples 'TO WHOM did you give the apples'
b. Answer: \# ghe go dato i pomi a dzani 3.DAT have 1 PS given the apples to John




\section{c. Answer: ghe go dato A dyANI i pomi \\ 3.DAT have 1 PS given to John the apples \\ 'I gave the apples to John' (Lit: 'I gave TO JOHN the apples')}

According to Cinque \& Rizzi (2016), cartographic analyses of clauseinternal foci of the type presented here are the most transparent way to explicitly express the fact that syntactic positions (and therefore anything related to word order) directly affect aspects of the interpretation, which can thus be read off the syntactic configuration. In sentences like (32b) the IO is narrow focus, i.e., the sole constituent carrying the new information that the question is asking for. The position of the IO in (32c) is an internal-merge one: the narrow focus IO occupies the same low focus position targeted by the narrow focus subject in (29b), (30b) and (31b). A structural parallel is proposed in the diagram in (33):

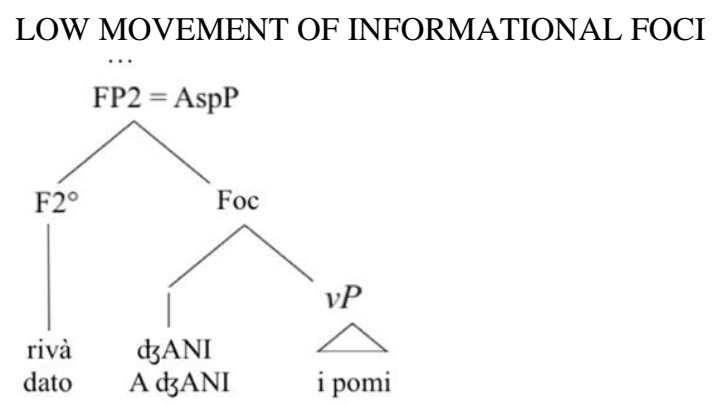

A brief remark before moving to the next section. While, structurally, the position targeted by lexically-restricted and non-lexically-restricted wh-elements, and by foci of any type, lies in the same portion of the middle field, it nonetheless appears theoretically undesirable to posit that all of these focal elements agree with / are attracted by the exact same feature, given that their quantificational properties are not identical. For Standard Italian, for example, we know that not only contrastive and informational focus, but also mirative and corrective focus can surface clause-internally (Cruschina 2012, Bianchi \& Bocci 2012, Bianchi 2013, a.o.), a pattern that is replicated in eastern Trevisan. While it would be incorrect to assume that all of these types of focalisation involve the same quantification, I maintain that the parallel movement properties of foci and wh-elements is legitimate, and supports the claim that these low movements are triggered by [focus], although the interpretive similarity brought forward by Horvath cannot be extended to all categories. I believe that a reconsideration of the structure of the LLP is in order, and that the possibility should be considered that what interacts with focal elements is not a simple focus projection but a full-fledged focal field (see Cruschina 2012 for a discussion of the HLP along these line). Therefore, what I call 'focus' here is actually a broad label that refers to distinct focal phenomena.

\section{From the grammar of $Q$ to the theory of WH-TO-FOC}

Cable's (2010) monograph had non-negligible consequences not only for the theory of wh-in situ, but also for the theory of interrogative wh-movement in general. In Bonan (2021), I argued in favour of an implementation of Q-particles in Romance, 
and analysed the clause-internal wh-elements of eastern Trevisan as linked to the Q-particle through a structural configuration of adjunction.

In what follows, I first explain why neither of the existing theories of northern Italian wh-in situ can account for the interrogative syntax of eastern Trevisan and similar wh-in situ languages that display clause-internal movement of wh-elements (§3.1). I then overview Cable’s (2010) main claims concerning the cross-linguistic grammar of Q-particles $(\$ 3.2)$ and, finally, propose a number of new theoretical and empirical reasons in favour of an implementation of silent Qparticles in the derivations of eastern Trevisan and, by extension, Romance ( $\$ 3.3)$.

\subsection{Against remnant-IP movement and (mere) covert movement}

Research into the syntax of wh-movement in Romance was first undertaken by Kayne (1972), on the basis of French data. Later, Kayne's (1994) 'antisymmetry', with its emphasis on strict binary branching and the ban on rightward movement, provided a very productive framework for the study of simple and complex interrogative inversion. Following this influential work, Munaro et al. (2001) and Poletto \& Pollock (2000) (and further related papers) extended the remnant-IP movement analysis to the syntax of interrogatives in French and NIDs. ${ }^{14}$ According to these studies, clause-internal wh-elements in NIDs undergo wh-movement to a high left-peripheral Spec, which is masked in the phonetic string because further movements take place that displace the whole remnant-IP to the HLP of the clause. The remnant-IP movement analysis was heavily criticised by Manzini \& Savoia $(2005 ; 2011)$, who claimed that clause-internal wh-elements are unmoved from their first-merge position in NIDs, i.e., fronted after Spell-Out, à la Huang (1982).

Here, I wish to argue that both approaches are at the least incompatible with the interrogative syntax of eastern Trevisan. It must be noted that an interesting account for the syntax of northern Italian wh-in situ was formulated in Munaro (1999), who claimed that the clause-internal wh-words of Bellunese surfaced in their external-merge position, and all observed intervention phenomena were the result of the presence of an interrogative operator that moved from within IP into what was called CP at the time, thereby determining the scope of the wh-word itself. Although Munaro's (1999) work is less well-known that the other studies mentioned above, his analysis comes closest to the approach that I adopt.

The eastern Trevisan data witness that the phenomenon of wh-in situ in NIDs (and beyond) cannot be explained as a simple instance of scope construal: if the clause-internal wh-elements of eastern Trevisan stayed in their external-merge site, à la Manzini \& Savoia $(2005 ; 2011)$, systematic rightward extraposition of $v \mathrm{P}-$ internal material would be required to derive the observed interrogative orderings. However, not only would an operation of the sort be ill-justified, but I have also shown that the post-focal material normally stays in situ in eastern Trevisan.

The question of the 'remnant-IP movement hypothesis' is more complex, and in what follows I shall show why its extension to eastern Trevisan and Romance

14 See also Uribe-Etxebarria (2002), Etxepare \& Uribe-Etxebarria (2005), Den Dikken (2003), a.o., for similar claims applied to other Romance and non-Romance varieties. Refer to Bonan (2021: 183) for a classification and discussion of Romance wh-in situ in light of the theory presented and implemented here. 
in general is undesirable. To understand the basics of this approach, consider the Bellunese example in (33), and its derivation in (34): ${ }^{15}$

(33) Se-tu 'ndat andé?

are $=$ you gone where

'Where did you go?'

(34) Input: [IP tu sé 'ndat [ andé $\varnothing]]^{16}$

(Bellunese)

a. Step 1: Op1P and IP are merged; the complex wh-element is attracted to SpecOp1P:

[Op1P [ andé $\varnothing] \mathrm{Op}^{\circ}$ [IP tu sé ndat <andé $\emptyset>$ ]]

b. Step 2: TopP and Op1P are merged: the participial phrase (PartP) that includes the trace of the complex wh-element, [ 'ndat $<w h>$ ], is attracted to SpecTopP: ${ }^{17}$

[TopP [PartP ndat <wh> ] Top ${ }^{\circ}$ [Op1P [ andé $\left.\varnothing\right]$ Op $1^{\circ}$ [IP tu sé <PartP> ]]]

c. Step3: G(round)P and TopP are merged; the subject clitic $t u$ is attracted to SpecGP:

[GP tu $\mathrm{G}^{\circ}$ [TopP [PartP ndat <wh> ] Top ${ }^{\circ}$ [op1P [ andé Ø] Op $1^{\circ}$ [IP <tu> sé ...

d. Step 4: ForceP and GP are merged, and the remnant-IP is attracted to SpecForce: ${ }^{18}$

[ForceP [IP sé ] Force $^{\circ}\left[\mathrm{GP}\right.$ tu $\mathrm{G}^{\circ}\left[\mathrm{TopP}\left[\mathrm{PartP}\right.\right.$ ndat <wh> ] Top ${ }^{\circ}$ [Op1P [ andé $\left.\varnothing\right]$ $\langle$ IP> ]]]]

e. Step 5: Op2P and ForceP are merged; $\varnothing$ is attracted to SpecOp2P:

[Op2P $\varnothing$ Op2 ${ }^{\circ}$ [FP [IP sé ] $\mathrm{F}^{\circ}$ [GP tu $\mathrm{G}^{\circ}$ [TopP [PartP ndat <wh> ] Top ${ }^{\circ}$ [Op1P [ andé $\langle\varnothing\rangle\langle\mathrm{IP}\rangle]$

Derivations along the lines of (34) are based on theoretical and empirical factors including, non-exclusively, Kayne's (1998) claim that there cannot be covert movement of any kind, and the assumption that the different sequences displayed by languages such as French and Bellunese at Spell-Out must reflect the interplay of the invariant structure of the HLP. For these authors, two what-words of French and Bellunese, and their close connection with SCLI, suggest that these target the same Spec in the HLP. Notably, Bellunese che is only able to surface clauseinternally and, like all other wh-elements in this language, it is construed with SCLI in answer-seeking interrogatives. Conversely, French que can only be fronted and must be combined with SCLI, as in the contrasts in (35):

15 According to the authors, wh-elements are composed of a pronounced part (the wh-word) and either a silent Restrictor (Poletto \& Pollock 2000) or the silent head of a complex Clitic Phrase (Poletto \& Pollock 2004), written as ' $\varnothing$ ' here. While I maintain that a left-peripheral derivation for wh-in situ is not tenable, the composite structure of interrogative wh-elements is in line with my analysis. This is one of numerous versions of Poletto \& Pollock's theory, which the authors have implemented steadily over the years. Nonetheless, the core arguments and assumptions have remained unchanged until their (2015) paper (refer to Poletto \& Pollock 2019 for an implementation that includes the llp in the dedivations.). 
(35)
a. Qu'as-tu mangé?
what $=$ have $=$ you eaten
'What did you eat?'
b. * Que tu as mangé?
what you have eaten
c. * As-tu mangé que?
have=you eaten what

In the 'remnant-IP movement' framework, the reason why que appears clauseinitially, while che occupies a clause-internal position at Spell-Out, is that only the latter requires complex computations to take place after wh-movement, which moves the whole IP to the HLP, as in the sketched contrast in (36):

REMNANT-IP MOVEMENT ANALYSIS: BELLUNESE VS. FRENCH

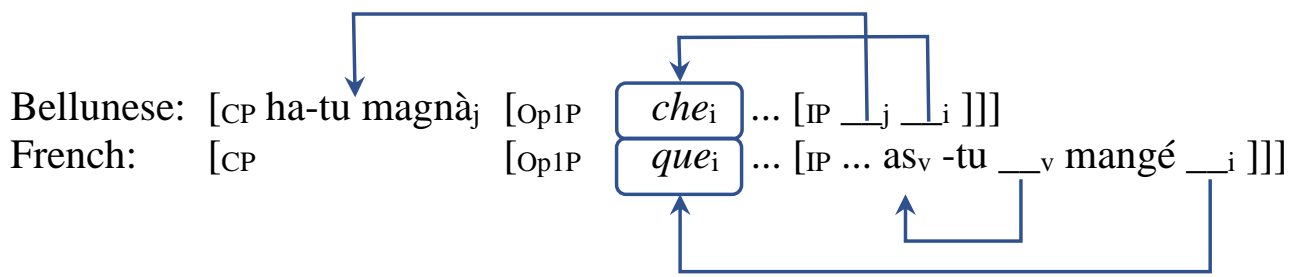

However, an extension of (36) to eastern Trevisan and all NIDs discussed in Manzini \& Savoia (2005) is empirically undesirable. The legitimacy of the parallel in (36) is threatened both on synchronic and diachronic grounds, and in the whole northern Italian domain "available evidence at best is neutral with respect to remnant movement" (Manzini \& Savoia 2011: 82). I overview some empirical and theoretical points against Munaro et al.'s approach here, and then offer a parallel of the cross-linguistic morphosyntax of in situ languages in $\$ 4-5 .{ }^{19}$

A first problem posed by the parallel in (36) is that, as already noted in Manzini \& Savoia $(2005 ; 2011)$, in all Romance languages but French the distribution of SCLI is orthogonal to the surface position of the wh-element. Normally, when a language requires SCLI in answer-seeking interrogatives, this is independently observed at Spell-Out. The only notable exception is that of French which, as illustrated in (37), disallows SCLI in constructions with wh-in situ:

As-tu mangé quoi ?
have=you eaten
'What did you eat?'

(French)

An analysis of French SCLI as an IP-internal phenomenon, as proposed in (37), is also problematic in light of works such as Roberts $(2007 ; 2010)$, in which interrogative clitics are convincingly argued to be instantiations of $\varphi$-features that the residual v2 environment in the interrogative HLP of French fails to pass to T. Additionally, a parallel between Bellunese che, /ke/, and French clause-internal

19 Further evidence against derivations along these lines is offered in Manzini \& Savoia (2011), Shlonsky (2012), Déprez et al. (2012;2013), Manzini (2014), a.o. 
quoi, /kwa/, is actually better justified. Observe the contrast in (38), which shows that quoi, like its Bellunese counterpart, can only surface clause-internally:

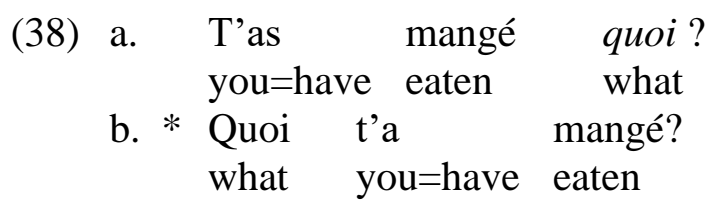

(French)

Quoi, which originated from Latin qui(d), was originally written as quoy, and only started displaying the modern orthography around 1740. The graph <oy> was pronounced /oi/ in Old French, then /we/ in Late Old French, and only moved to the contemporary realisation /wa/ in the Modern French period (Boyd-Bowman 1980; Gess 1996). It is therefore highly plausible that Late Old French quoy was pronounced $/ \mathrm{kw} /$ which, along with the distribution shown in (38), makes French quoi closer to Bellunese / $\mathrm{ke} /$ than its clitic counterpart $/ \mathrm{k} /$.

A second point against derivations that include left-peripheral movements of all IP-internal material relates to the observation that one does not expect long construals to be possible in a language which derives wh-in situ left-peripherally (Shlonsky, pc.); however, these are not only possible in eastern Trevisan, Lombard and Venetan in general, but also in Bellunese, as shown in (39):
a. À-tu
dit che l'à
comprà
che?
have=you said that he=has bought what 'What did you say he bought?'
b. À-tu dit che l'é
have=you said that he=is
'Where did you say he went?'
'ndat andé?
gone where

(Munaro 1999: 72(1.100-102))

Munaro (1999) explained examples such as (39) in terms of the ability of whelements in subordinate clauses to correctly establish an interpretive connection with the "abstract operator in the matrix CP that is legitimised by the interrogative inflection on the matrix verb [my translation]". However, the existence of long construals is problematic for the remnant-IP movement analysis, where wh-in situ should target a left-peripheral wh-projection systematically.

A third point relates to the complexity of the proposed derivations, which makes them not only inapplicable to numerous wh-in situ languages, but also challenging from a language acquisition perspective at the very least. It is indeed not clear how the language learner could infer the presence of numerous displacements of trace-containing constituents such as those of (34) from the linguistic input. Moreover, as previously observed, these derivations also "face the restrictiveness problem generally imputed to Kaynian movement, namely that Chomsky's (1995) Economy principle (to the effect that movement is possible only if necessary) does not hold of them" (Manzini \& Savoia 2011: 82). It is indeed my belief that a derivationally more economical and acquisitionally more transparent explanation ought to be sought.

A fourth point is that if the eastern Trevisan clause-internal wh-elements moved to the HLP, orders in which the wh-element surfaces higher than its external- 
merge position in the phonetic string would require a displacement of what follows the wh-element at Spell-Out, prior to wh-movement. As Ur Shlonsky (pc.) points out, this could possibly be done by positing the existence of an FP higher than the remnant that moves to the HLP, either lower than OP1P in the HLP, as suggested in (40), or in the highest portion of IP, as in (41):

(40) Input: [IP te ghe ga dato i pomi a ki ]

a. Step 1: Merge FP and IP; attract the DP to SpecFP:

[FP i pomi $\mathrm{F}^{\circ}$ [IP te ghe ga dato _ $\mathrm{j}_{\mathrm{j}}$ a ki ]]]

b. Step 2: Merge OP1P and FP, and attract the wh-element to SpecOp1P:

[Op1P a $\mathrm{ki}_{\mathrm{i}} \mathrm{Op} 1^{\circ}$ [FP i pomi $\mathrm{F}_{\mathrm{j}}^{\circ}$ [IP te ghe ga dato _ $\mathrm{j}_{\mathrm{j}} \mathrm{i}$ ]]]

c. Step 3: Further left-peripheral displacements that derive the observed surface order.

(41) Input: [IP te ghe ga dato i pomi a ki ]

a. Step 1: Topicalisation of the DO to a FP higher than IP:

[FP i pomi $\mathrm{T}^{\circ}$ [IP te ghe ga dato _ $\mathrm{j}_{\mathrm{j}}$ a ki ]]]

b. Step 2: Various movements that displace the wh-element, the verb, and the subject clitic to the HLP; when the remnant-IP is attracted to the HLP, the DO internally-merged high in the IP is spared: [CP [IP ... ghe ga ... ] $]_{I P}$ tu dato _ ${ }_{\mathrm{j}}$ a ki [FP i pomi $\left.\left.\mathrm{T}^{\circ} \ldots \mathrm{IP}\right]\right]$

However, movements of the post-wh material such as those in (40) and (41) would be stipulative and come with no independent evidence in their favour.

My claim is further supported by Manzini \& Savoia's (2011) observation that, in the northern Italian domain, not only long construals such as the ones in (39), but also wh-in situ in indirect questions and in islands is common. Data from Lombard are reported in (42), (43), and (44), respectively, which exclude the possibility of a left-peripheral derivation for northern Italian wh-in situ:

(42) 'penset (k) $\quad \varepsilon$ 'faye ko'ze?

(Strozzense)

think 2 Ps (that) he does what

'What do you think he is doing?'

(Manzini \& Savoia 2005: 591(155))
a. so mia dyr'mi ndo'e / fa 1 ko'm $\varepsilon$ knowips NEG to.sleep where / do it how 'I don't know where to sleep / how to do it'
b. al ho mia durmi ndo' $\varepsilon$ / pityra l kome (Grumellese) it know 1 PS NEG to.sleep where / to.paint it how 'I don't know where to sleep / how to paint it'
(Strozzense)

(Manzini \& Savoia 2011: 83(5b))

$\begin{array}{lllllllll}\text { (44) a. penset } & \text { ke } & l & \varepsilon & \text { bela } & \text { la } & \text { spuzo } & \text { de } & \text { ki ? } \\ \text { you.think } & \text { that } & \text { she } & \text { is } & \text { good.looking the } & \text { wife } & \text { of } & \text { whom }\end{array}$ 'For which $x, x$ is a wife, the wife of $x$ is good looking?'
b. $\mathrm{g}$ a $\mathrm{i}$ vest $\mathrm{i}$ om ke majo ki ?
there have they seen the men that eat what
'For which $x, x$ is food, they have seen the men who eat $x$ ?'
(Passiranese) 


\section{c. E 1 nat via henso haly'da ki ? \\ is he gone away without greet who \\ 'For which $x, x$ is a human, he left without greeting $x$ ?' \\ (adapted from Manzini \& Savoia 2011: 89(11) $)^{20}$}

Given that a derivation in Munaro et al.'s terms is incompatible with the interrogative morphosyntax of eastern Trevisan and of all NIDs in Manzini \& Savoia (2005), to posit that this type of derivation is nonetheless at play in Bellunese would entail the presence of a major typological divide. Such a typological gap could be plausible between Bellunese and Chinese, but its postulation is not advisable between Bellunese and closely-related eastern Trevisan and/or Lombard dialects. While none of these existing analyses account for the totality of the phenomena observed in wh-in situ languages, I will claim that the correct analysis consists in the implementation of Munaro's and Manzini \& Savoia's theories in light of recent work on wh-in situ in languages with phonetically-realised Q-particles, namely Cable (2010), whose main claims I overview in $\$ 3.2$.

\subsection{The grammar and parameters of $Q$}

Cable (2010) argued that, cross-linguistically, wh-fronting is not triggered by properties of the wh-element but targets the features of the Q-particle. Indeed, the felicity of Tlingit wh-questions depends upon the locality of the Q-particle to the HLP, while the locality of the wh-element is irrelevant. This is illustrated in (45a), in which the Q-particle sá attached outside of the island to extraction makes it possible for the wh-word wáa ('how') to surface within the island, while sá in a more embedded position gives rise to ungrammaticality, as in (45b):

$$
\begin{aligned}
& \text { a. [[ WÁA kwligeyi } \left.\left.{ }_{\mathrm{CP}}\right] \text { xáat }{ }_{\mathrm{NP}}\right] \text { sá } \quad \mathrm{i} \text { tuwáa sigóo ? } \\
& \text { how it.is.big. ReL fish Q your spirit it.is.glad } \\
& \text { 'HOw big a fish do you want?' } \\
& \text { b. * [[ WÁA sá kwligeyi CP] xáat NP] i tuwáa sigóo ? } \\
& \text { how Q it.is.big.REL fish your spirit it.is.glad } \\
& \text { Tlingit (Cable 2010: 7-8(10)) }
\end{aligned}
$$

Contrasts like those in (45) led Cable to claim that the rules for forming whquestions in Tlingit are sensitive exclusively to the position of the Q-particle, and that only the features of the Q-particle can be referenced by those rules. Accordingly, there is no such thing as 'pied-piping' of wh-elements, but rather QPfronting, an overt movement that only targets $\mathrm{Q}$ yet results in the parasitic movement of the wh-element to the HLP. Observe the Tlingit question in (46), in which the fronted wh-word wáa is followed directly by the Q-particle sá:

(46) WÁA sá sh tudinookw i éesh?

how $Q$ he feels your father

(Tlingit)

'HOW is your father feeling?'

(Cable 2010: 3(1), from Dauenhauer \& Dauenhauer 2000: 138)

\footnotetext{
${ }^{20}$ Example are given as 'adapted' when I change the gloss/translation (some sentences, for instance, were originally translated into Italian) or add brackets/arrows in the example.
} 
For Cable, Tlingit wh-elements have the structure in (47):

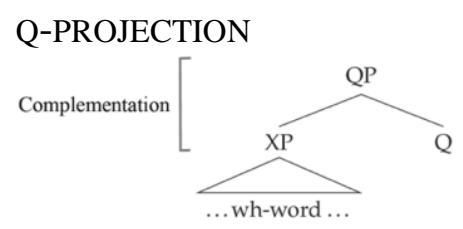

In Q-projection configurations such as the one in (47), the Q particle selects the whword as its internal argument, to the effect that the projection that immediately dominates the Q-particle is of a different type with respect to the projection that immediately dominates its sister, i.e., the wh-word. From this particular configuration it follows that attraction of the Q-feature to the HLP entails that the entire QP is moved, as in (48):

\section{WH-FRONTING AS AN EFFECT OF Q-MOVEMENT}

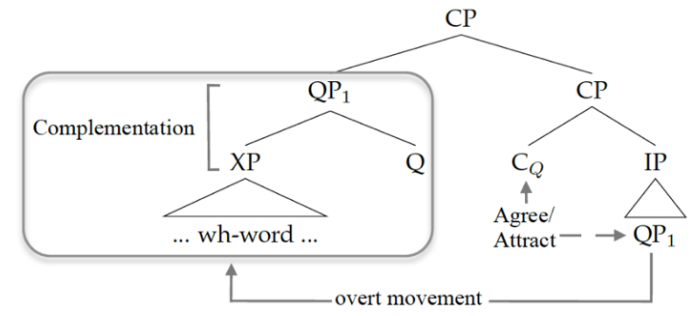

(Cable 2010: 39(53))

Cable explained that the analysis in (48) is true of all total-fronting languages, also those which lack phonetically realised Q-particles. This analysis of total fronting led to the establishment of a new typology of wh-in situ, which for Cable comprises at least two distinct syntactic types:

i. Q-PROJECTION LANGUAGES: languages where the Q-particle takes its sister as complement, as in QP-fronting languages, but QP-movement occurs covertly (such as Sinhala);

ii. Q-ADJUNCTION LANGUAGES: languages where the Q-particle adjoins to its sister and moves to the HLP alone (such as Japanese, or Korean). ${ }^{21}$

In Q-projection in situ languages, the structure of wh-elements is the same as in Tlingit, and the difference between the two languages lies in the timing of movement, as in the diagram in (49):
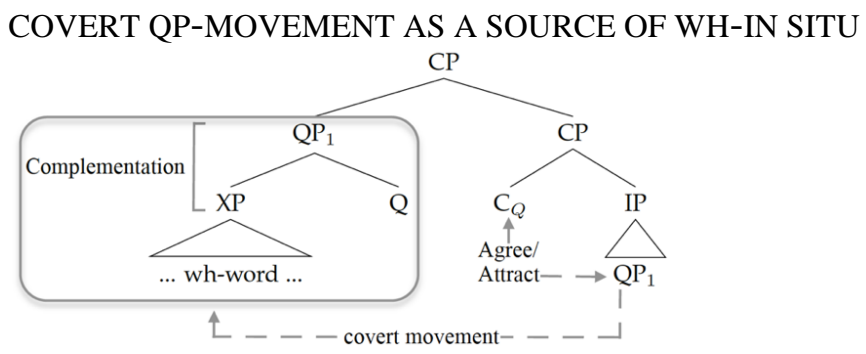

(Cable 2010: 86(3))

$21 \quad$ Adjunction of Q could plausibly be dispensed with using a concept such as that of a 'free morpheme'. I leave the investigation of this point for further research. 
An example of a Q-projection in situ language is SOV Sinhala, as in (50):

(50) Chitra MONAWA da gatte?
Chitra what

(Sinhala)

'WHAT did Chitra buy?'

(Cable 2010: 31(32), originally in Kishimoto 2005: 3)

Conversely, in Q-adjunction languages, the node which immediately dominates the Q-particle and its sister is not a QP, but rather of the same type as the sister of Q, as illustrated in (51):

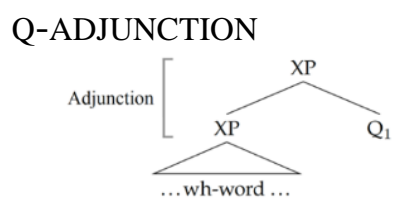

The main property of the Q-adjunction configuration is that the Q-particle moves alone to the HLP, stranding the wh-element clause-internally. Examples of Qadjoining languages are reported in (52):
a. John-ga NANI-O kaimasita ka?
John-NOM what-ACC bought.polite Q
'WHAT did John buy?'
b. ETI-EY sensayng-nim-i ka-sipni-kka?
where.to teacher-HON-NOM go-HON-Q
'WHERE did the teacher go?'

(Japanese)

(Korean)

(Cable 2010: 89(12-13))

The derivation of wh-in situ in Q-adjoining languages is sketched in (53); this was inspired by Hagstrom's (1998) analysis of Japanese wh-questions.

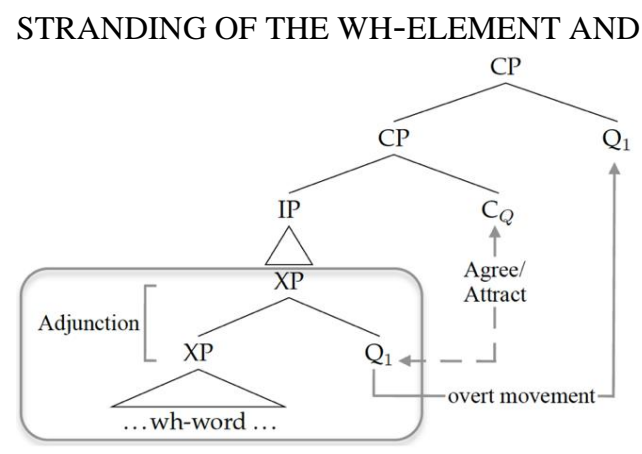

(Cable 2010: 39(52))

Cable consequently singled out the existence of three main Parameters responsible for most cross-linguistic variation in the morphosyntax of whquestions, which I summarise in (54): ${ }^{22}$

(54) CABLE'S PARAMETERS

22 Cable also formulated 'Agreement' and 'Multiple Wh-Agreement' Parameters. While the latter is not relevant in NIDs, I discuss the Agreement Parameter in $§ 5$. 
PROJECTION PARAMETER: Q-PROJECTION VS. Q-ADJUNCTION

In Q-adjunction languages, $Q$ adjoins to its sister and their mother is of the same category as the sister (in most cases, a Wh-projection). In Q-projection languages, Q takes its sister as complement, and so the node minimally dominating the $\mathrm{Q}$ and its sister is a $\mathrm{QP}$.

Q-MOVEMENT PARAMETER: OVERT MOVEMENT VS. COVERT MOVEMENT

In overt Q-movement languages, the highest syntactic copy of a Q-particle is pronounced. In covert Q-movement languages, the lowest syntactic copy of a Q-particle is pronounced.

Q-PRONUNCIATION PARAMETER: PHONETICALLY-REALISED VS. SILENT

In some languages, like Tlingit, the Q-particle has phonological content. In other languages, the Q-particle is phonologically null.

I now argue that the implementation of silent Q-particles in Romance is not an ad hoc choice, but rather one that is well supported both theoretically and empirically.

\subsection{In favour of an implementation of $Q$-particles in Romance}

Not only does Cable himself provide multiple reasons in support of the existence of Q-particles in languages like Standard English in which these particles are silent, but authors such as Aboh \& Pfau (2011) also explicitly dissociate wh-movement from interrogative force. Accordingly, wh-elements are not inherently interrogative and do not participate in clause typing. For them, wh-elements in answer-seeking interrogatives may be cross-linguistically required only for the identification of the content of the question. The legitimacy of these claims, I believe, is made particularly clear in Asian languages such as Chinese, in which wh-words are indefinites or polarity items, and have no quantificational force of their own, or in Albanian, where so-called ' $\mathrm{k}$-words' need moving into a focal projection to be interpreted as interrogative (Turano 1998).

It is also acknowledged that wh-words are not exclusively employed in interrogative sentences. Observe the use of the adverbial dove ('where') in (55):

a. DOVE ve se-o conossui?
where REFL are=you met
'WHERE did you meet?'
b. el ristorante dove ke ve sé conossui
the restaurant where that REFL are met
'The restaurant where you met'

While (55a) is an interrogative, (55b) is a relative clause. Rizzi (1990) argues that wh-words are associated with both $[+w h]$ and $[+q]$ features, and their specification changes depending on the context, with the effect that dove is $[+w h ;+q]$ in $(55 \mathrm{a})$ and [+wh;-q] in (55b). Recall that I have claimed that wh-elements check a low [focus]-feature in interrogatives. What is the status of [wh] in these structures? Chomsky (1995) assumes that the insertion of formal features must have some output effect. Plausibly, [wh] and [focus] are always inherently present in the whelement: while the former is valued in relatives, [focus] is valued in interrogatives. The featural specification proposed for wh-elements in Rizzi (1990) should thus be amended as in (56): 


\section{(56) FEATURAL SPECIFICATION OF WH-WORDS INHERENT FEATURES: [wh;focus] ACQUIRED FEATURE: [q]}

In answer-seeking interrogatives, the inherent feature of the wh-element that gets activated is the one that has an output effect, [focus], and the [q]-feature is 'acquired' (not by the wh-word itself but rather by the XP projected either by the wh-word, in Q-adjunction, or by the Q-particle, in Q-projection). Substantial crosslinguistic evidence is thus available to support the claim that the role of Q also ought to be considered in the derivation of wh-interrogatives in those languages that do not have phonetically realised Q-particles. Moreover, in the cartographic enterprise the existence of a functional head in one natural language is considered enough to posit the existence of that same head in the functional spine of all languages: in such a framework, it is theoretically undesirable not to posit the cross-linguistic presence of Q-particles in the computation of wh-interrogatives.

Most contributions on wh-in situ in Romance have hitherto been characterised by the common assumption that there is a connection between the clause-internal wh-element and a null operator in the HLP. It is often challenging to distinguish (both empirically and conceptually) the overt movement of a silent Qparticle into the HLP from the licensing of a silent interrogative operator in the same left-peripheral position. By looking at the eastern Trevisan phonetic string alone, it is impossible to determine whether the silent 'Q-element' under consideration starts out IP-internally, as a Q-particle in the sense of Cable, or is a more standard operator base-generated in the HLP. One of the core reasons to adopt Cable's analysis, treating the eastern Trevisan Q as an IP-internal element, is that there is empirical evidence that the realisation of SCLI in eastern Trevisan is closely linked to the presence of overt interrogative movement into the HLP.

Such evidence in favour of an implementation of silent Q-particles in eastern Trevisan and, by extension, Romance comes from the syntax of eastern Trevisan parké, a regular why-word in the sense of Rizzi (2001) and Stepanov \& Tsai (2008). Parké can only surface in the HLP, i.e., where it is generated, and is incompatible with subject-inversion, as in (57):

$$
\begin{aligned}
& \text { a. parké te sì ndaa al } \\
& \text { why you= are } \text { gone }_{\mathrm{F}} \text { to.the } \\
& \text { 'Why did you go to the market?' } \\
& \text { b. * te sì nda parché al } \\
& \text { you are gone } \text { garcà? }_{\mathrm{F}} \text { why to.the market }
\end{aligned}
$$

Interestingly, Bonan \& Shlonsky (2021) noted that, in the context of long extraction of parké, SCLI is only realised when parké is long-construed, as in (58).
a. parké te dizi [ ke a te ga tamà ]? why you $=$ say that $\mathrm{she}=$ you has called 'What is $x, x$ a reason, you say [that she called you] because $x$ ?'
b. parké ${ }_{i}$ dizitu $\left[\mathrm{ke} \_\right.$_ a te ga tamà ]? why say=you that she $=$ you has called


'What is $x, x$ a reason, you say [that she called you because $x$ ]?'

Given the incompatibility of matrix parké in constructions with SCLI, one normally does not expect (58b) to be felicitous. For Bonan \& Shlonsky (2021), in the absence of interrogative movement through FinP, i.e., in matrix questions in which parké is externally-merged directly in the HLP, interrogative SCLI is not triggered. In contrast, when parké is externally-merged in the embedded HLP and then extracted into the matrix HLP, passage through SpecFin is present and SCLI is triggered. Empirical evidence of this type suggests that overt interrogative movement through SpecFin is needed to have SCLI: in eastern Trevisan matrix wh-questions with a clause-internal wh-element, obligatory SCLI witnesses the presence of overt interrogative movement to the HLP, which can be understood as in (59).

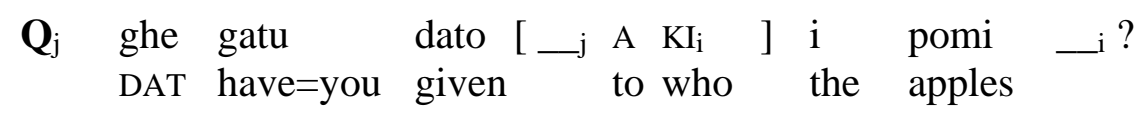

In the case of matrix wh-interrogatives, the interrogative element that moves overtly to the HLP through SpecFin is a silent Q-particle generated within the clausal domain, as sketched in (59), in total fronting it is a QP, and in yes/no questions, a IP-internal polar particle à la Holmberg (2015).

\section{The theory of WH-TO-FOC}

Cross-linguistically, wh-in situ is either the result of covert QP-fronting or overt fronting of the Q-particle of a configuration of Q-adjunction (Cable 2010). I have shown that eastern Trevisan has overt interrogative movement into the HLP, which is active throughout the derivation of answer-seeking interrogatives, as witnessed by the compulsory realisation of SCLI. From this and the fact that overt wh-fronting is always fronting of a QP, I have claimed that the virtually free alternation between total fronting and low peripheral fronting in eastern Trevisan cannot be attributed to an alternation between overt and covert QP-fronting: it must rather be a byproduct of the simultaneous existence of Q-projection and Q-adjunction.

\subsection{Technicalities of WH-TO-FOC}

The configuration of Q-adjunction, responsible for the clause-internal stranding of wh-elements at Spell-Out, is as in (60).

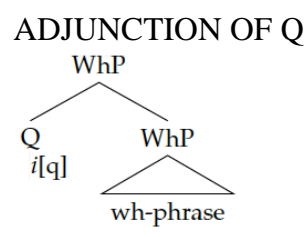

In $\S 2, I$ argued that the derivation of eastern Trevisan 'wh-in situ' interrogatives involves low focus movement that is responsible for the observed IO>DO and ADV $>$ DO surface orderings. This movement is done as in (61): 
(61)

FOCUS-AGREEMENT LEADING TO FOCUS-MOVEMENT INTO THE LLP

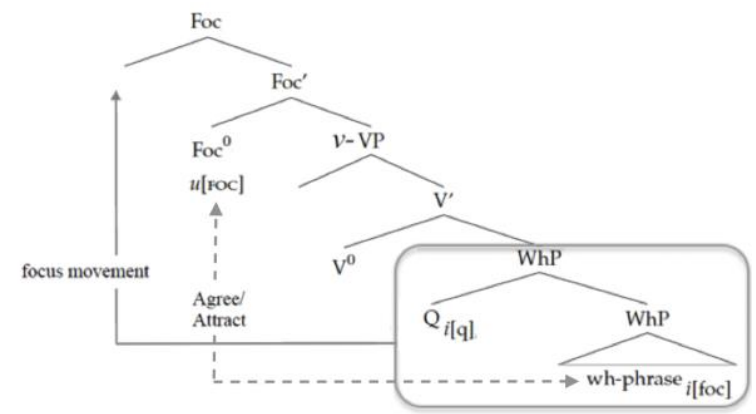

In (61), the inherent feature that is valued on the wh-element is [focus]. This interpretable feature agrees with its uninterpretable counterpart in $\mathrm{Foc}^{\circ}$ and then is attracted into SpecFoc. We can attribute the presence of overt low movement to a requirement for AGREE+MOVE. In line with Bonan (2021), I shall henceforth refer to this low focus movement as WH-TO-FOC.

However, the additional need to check a high left-peripheral [q]-feature à la Cable (2010) makes (61) only a partial version of the derivation of eastern Trevisan wh-in situ; the left-peripheral step of the derivation is sketched in (62): ${ }^{23 ; 24 ; 25}$

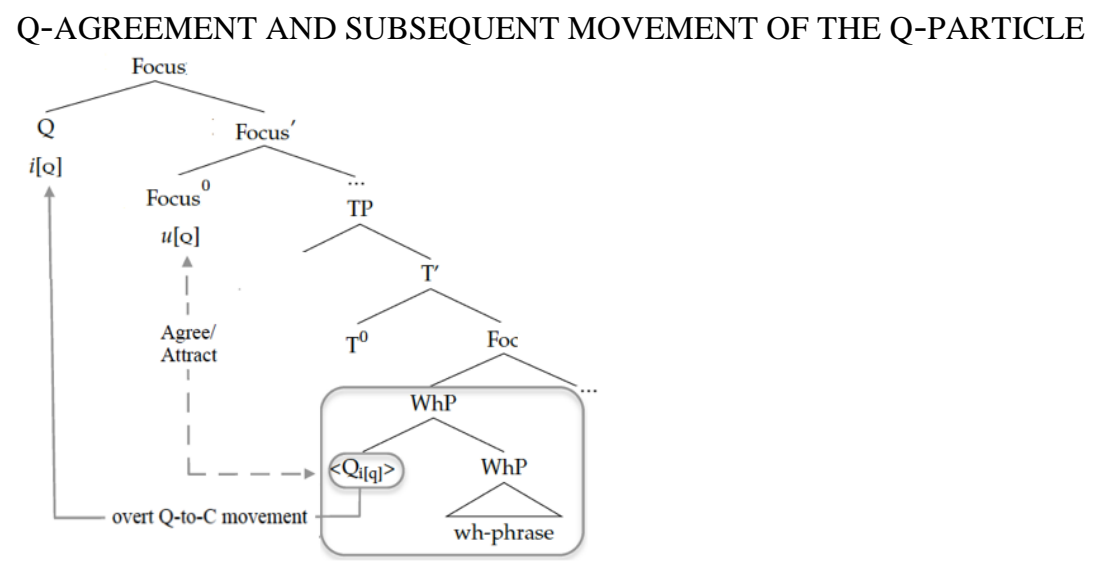

In (62), the uninterpretable [q]-feature in Rizzi's (1997) left-peripheral Focus ${ }^{\circ}$ agrees with the interpretable counterpart on the Q-particle, which is adjoined to the frozen-in-place wh-element in SpecFoc. Because of the requirement for AGREE+MOVE, the Q-particle is attracted to SpecFocus. ${ }^{26}$

23 The Q-particle dealt with here is not a 'sentential particle' (Munaro \& Poletto 2003), nor a silent counterpart of northern Italian 'wh-doubling' (Manzini \& Savoia 2005, Poletto \& Pollock 2015, a.o.).

24 In light of my and Cable's discussions, Rizzi's (1997) FocusP should rather be called Q(uestion)P. I prefer to keep the original terminology for the sake of clarity. The presence of overt interrogative movement follows from the setting of the Movement Parameter (\$3.2). While Cable (2010) suggested we "tentatively attribute the setting of this parameter to the presence or absence of EPP", I adopt an alternation in terms of 'AGREE+MOVE' vs 'AGREE alone' (Miyagawa 2009). Whether a Q-particle overtly moving to the HLP is sufficient to determine the scope of the clause internal wh-element remains to be determined. Luigi Rizzi (pc.) suggests that an additional mechanism such as feature movement à la Chomsky 
The term frozen-in-place comes from Rizzi's (2006) formulation of Criterial Freezing, i.e., the assumption that a phrase that enters into a configuration dedicated to the expression of a scope-discourse-property, called a criterial configuration, is frozen and becomes unavailable to further movement operations. Given that I am suggesting that the low peripheral focus projection, Foc, is a criterial one, it is important to make the point that the movement in (62) does not violate Criterial Freezing. Recent work has shown that there exist complex cases in which no obvious interpretive problem arises from moving a criterial configuration as a whole (without 'undoing' it) or from extracting an element from a criterial phrase "if no other constraint is violated" (Rizzi 2015: 9). Consider the complex wh-phrase in (63), which contains two criterial features, F1 and F2: a [q]-feature on the specifier and a corrective focus feature on the lexical restriction.

$$
\begin{array}{ll}
\text { quantiQ } & \text { ARTICOLIFoc }] \\
\text { how many } & \text { ARTICLES }
\end{array}
$$

(Rizzi 2015: 8(22))

Rizzi argued that once the phrase in (63) is in the HLP of an embedded question, it cannot further move to the corrective focus position in the main clause, as in (64):

(64) a. Non so [ quanti $Q$ ARTICOLIFoc $]_{i} Q$ abbiano pubblicato _ $\mathrm{i}$ NEG know1Ps how.many articles Q have 3 PP published 'I don't know how many ARTICLES they have published (not books)'

b. * [Quanti ARTICOLI ] Foc non so __i Q abbiano pubblicato _ how.many articles Foc NEG know1Ps Q have published 'How many ARTICLES I don't know they have published (not books)' Italian (adapted from Rizzi 2015: 8(23))

However, Rizzi also argued that, while a whole phrase satisfying a criterion cannot move further, an element can be sub-extracted from a criterial configuration. For instance, an adnominal PP can be felicitously sub-extracted and clefted, as in (65):

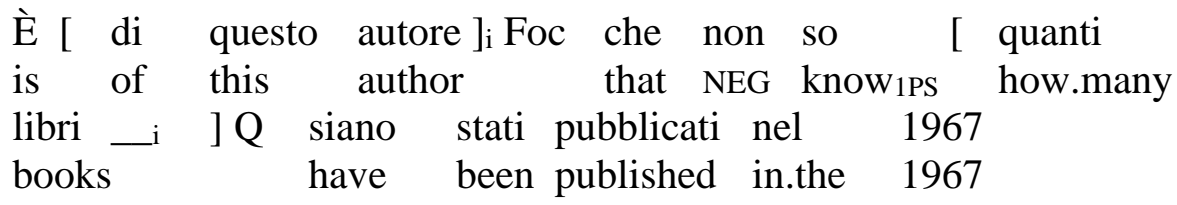

'It is by this author that I don't know how many books were published in 196' Italian (adapted from Rizzi 2015: 9(26))

Similarly, it appears that an entire criterial configuration can be moved as a whole. For instance, an indirect question can be clefted or topicalised, as long as the criterial configuration is not 'undone', as illustrated in (66):

(66) a. È [[ quantiQ libri di questo autore] Q [ siano stati pubblicati

(1995) might indeed be needed at the moment of interpretation. I leave the question for further work, although it seems to me that, semantically, the framework that is presented here does not require an operation of the sort. 
is how.many books of this author have been published nel 1967]]i che non è chiaro in.the 1967 that NEG is clear

'It's how many books by this author were published in 1967 that isn't clear'

b. [[ Quanti libri di questo autore] Q [ siano stati pubblicati how.many books of this author have been published nel 1967]]i non lo so davvero _ _i

in.the 1967 NEG it knowips really

'How many books by this author were published in 1967, I really don't know'

Italian (adapted from Rizzi 2015: 9(27))

The movement options in (65) and (66) led Rizzi to revise his formulation of Criterial Freezing reported in (67), by making reference not to the criterial phrase but to the criterial goal, i.e., the element carrying the criterial feature, as in (68):

(67) CRITERIAL FREEZING (Rizzi 2006;2010)

An element satisfying a criterion is frozen in place.

(68) CRITERIAL FREEZING (Rizzi 2015)

In a criterial configuration, the criterial goal is frozen in place.

I maintain that in the operation called WH-TO-FOC only the wh-phrase, i.e., the criterial goal of low focus movement, is frozen-in-place, and that the subsequent extraction of the Q-particle is a legitimate operation. However, a re-assessment of Rizzi's (1996) original Wh-Criterion is in order, which in light of my discussion appears more composite than we used to think. Accordingly, the Wh-Criterions is composite and comprises two chained Criteria: a Focus-Criterion and a Q-Criterion.

It is noteworthy that QP-movement (formerly 'wh-fronting') is triggered by the same [q]-feature in the HLP. Although I do not wish to address this type of movement here, I believe that the theory of WH-TO-FOC imposes a reconsideration of Chomsky's concept of 'successive-cyclic movement' of wh-elements, which in languages like eastern Trevisan could be fuelled by the need to check [focus]. While this observation is incompatible with Chomsky's (2005) original formulation of phase theory in which only $v \mathrm{P}$ and CP were phases, it is in line with recent views of 'dynamic phase edge' whereby what counts as a phase is the highest projection of a domain (Bošković 2014 and related studies). Accordingly, in eastern Trevisan and similar languages, the edge of the low phase is not SpecvP but SpecFoc.

In what follows, I wish to show that the theory of WH-TO-FOC is legitimate not only in light of the interrogative syntax of eastern Trevisan, but also in that of the diachronic evolution of well documented Asian languages such as Japanese and Chinese. I argue that Trevisan pairs with Old Japanese and Archaic Chinese in that it has not yet lost the requirement for MOVE.

\subsection{On language change}

Works on pure wh-in situ have illustrated that there exist languages which have undergone interesting typological changes. Watanabe (2003) claims that Japanese 
displayed overt fronting into the HLP during the Nara period ( $8^{\text {th }}$ century). ${ }^{27}$ This observation, in light of Cable's work, would suggest that Japanese went from being a Q-projection language to a Q-adjunction one. Instances of the movement under consideration are provided in (69):
a. 何物鴨
御狩
人之
折而
将挿頭
NANI-WO-ka-mo mikari-no fito-no
ori-te
kazasa-mu
what-ACC-Q-MO hike-GEN person-NOM
pick-CONJ wear.on.hair-will
'WHAT should hikers pick and wear on the hair?'
b. 何処従鹿妹之来而夢
IZUKU-YU-ka imo-ga iriki-te yume-ni mie-tsuru
where-through-Q wife-NOM enter-CONJ dream-LOC appear-PERF
'FROM WHERE did my wife come and appear in my dream?'

Old Japanese (Watanabe 2003: 182(5))

An evolution path different from the one just mentioned actually follows from Aldridge's (2009) understanding of the examples in (69). According to Aldridge, Watanabe's (2003) claim for overt high left-peripheral movement is unsuitably based on his assumption that genitive subjects are canonically located in SpecIP, meaning that a preceding wh-element must be located higher than IP, i.e., in the HLP. For Aldridge, genitive subjects rather stay in Spec $v \mathrm{P}$, as demonstrated by the observation that GENITIVE is not the structural case assigned by the finite $T$. From this observation, a WH-TO-FOC movement analysis along the lines of (70) becomes available for the clause-internally moved wh-elements of Old Japanese:

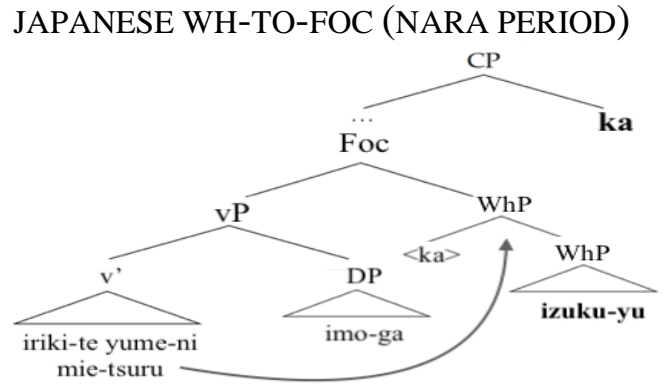

The evolution from Old Japanese WH-TO-FOC as in (70) to present-day unmoved wh-in situ can be understood as a consequence of the loss of the requirement for MOVE (refer to $\$ 5.1$ for an amendment of the Movement Parameter).

The Japanese evolution from WH-TO-FOC to mere focus-agreement featured a phase characterised by optionality during the Heian period $\left(9^{\text {th }}-12^{\text {th }}\right.$ century), as reported by Watanabe (2003). It seems tenable to understand this type of parametric change as an evolution in the direction of maximal simplicity, obtained through a negative setting of the requirement for AGREE+MOVE to just AGREE: during the Heian period, the new setting was being acquired, but was not yet generalised.

Low-moved wh-elements are also attested in Archaic Chinese (Warring States period, $5^{\text {th }}-3^{\text {rd }}$ century BCE), in a "position for interrogative and other focus

27 I am thankful to Hiromune Oda for pointing this out at IGG 2019, and then more recently for sending over a copy of Dadan (2019). 
constituents in the edge of $v$ P" (Aldridge 2010: 6; also refer to Li 1962 and Peyraube 1997 for similar claims), as exemplified in (71) and (72):
a. 天下 之 父歸 之, 其焉往? world GEN father settle here 3.GEN son where go

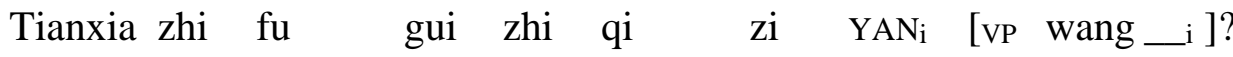 'If the fathers of the world settled here, WHERE would their sons go?'
b. 吾 誰 欺? 欺 天 乎?
$\mathrm{Wu}$ SHEI $_{\mathrm{i}}$ [vp qi _i ]? Qi tian hu?
I who deceive deceive Heaven Q
'WHO do I deceive? Do I deceive Heaven?'

Archaic Chinese (Aldridge 2010: 2(2))

(72)
a. 孔子 系 取 焉?
Kongzi xi qu yan
(Archaic Chinese)
Confucius what approve.of in.him
'What did Confucius approve of in him?'
b. 客何好?
Ke he hao
guest what like

'What does the guest like?'

(Peyraube 1997: 6-7(5-6))

Aldridge proposed an understanding of orders such as those in (71) and (72) that challenges the widespread assumption that the existence of constructions with preverbal objects in Archaic Chinese is evidence that Pre-Archaic Chinese had ov basic word order. ${ }^{28}$ For Aldridge, wh-elements and focused preverbal objects are not externally-merged in their surface positions in the examples above, but attracted there by a [focus]-feature. It is thus possible to propose an analysis of wh-in situ in terms of WH-TO-FOC also for Archaic Chinese, along the lines of (73):

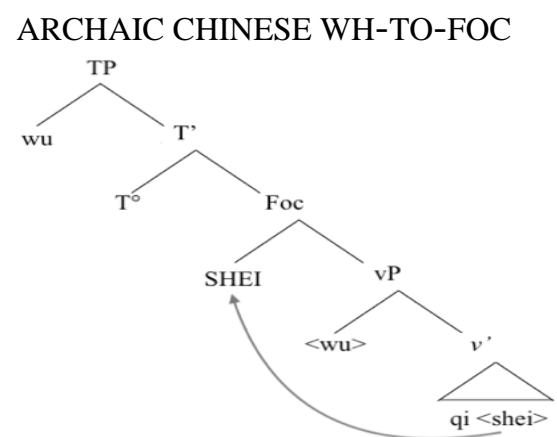

According to Aldridge, proper wh-in situ began to emerge in Chinese from the Han Dynasty ( $2^{\text {nd }}$ century BCE to $2^{\text {nd }}$ century CE). Instances of real wh-in situ from that era are provided in (74a), in which the wh-word shei ('who') follows the

28 For further evidence that the base order of Archaic Chinese was not SOV but SVO, see Peyraube (1997). 
preposition $y u$ ('with'), and in (74b), where the wh-phrase he yuan ('what complaint') remains in post-verbal position:

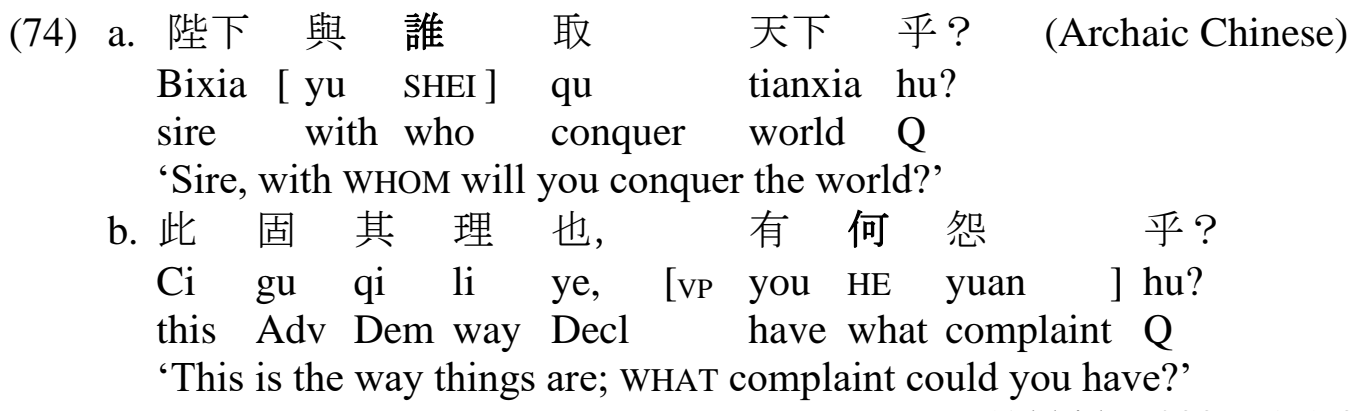

(Aldridge 2009: 56(70))

Following the theory presented in this paper, the main difference between Archaic and present-day Chinese with respect to the surface position of the interrogative wh-element is a by-product of the fact that the latter has just focus agreement. Similarly to Japanese, Chinese answer-seeking wh-interrogatives evolved from what looks like eastern Trevisan WH-TO-FOC to modern-day unmoved in situ. This was a consequence of the loss of the requirement for MOVE that, according to Aldridge (2010), must have been completed during the Han Dynasty period.

\subsubsection{More on Chinese}

I would now like to briefly outline a parallel between the movement properties of wh-elements and of contrastive foci in present-day Chinese. Following Gao (1994) and Paris (1998), Badan \& Del Gobbo (2010) and Badan (2015) produced overviews of the functional spine of Mandarin Chinese, and argued that different focus strategies adopt different syntactic behaviours in this variety: so-called lianfocus ('only'-focus) moves obligatorily to the HLP, while bare focus stays in situ. Examples are reported in (75) and (76), respectively:

$$
\begin{aligned}
& \text { Lian ZHE BEN SHU Lisi dou bu xihuan } \\
& \text { even this CLAS book Lisi all not like } \\
& \text { 'Even this book, Lisi does not like.' }
\end{aligned}
$$

(adapted from Badan 2015: 28(9))

$\begin{array}{lllllll}\text { (76) a. } & \text { Lisi bu xihuan } & \text { ZHE BEN } & \text { SHU } \\ & \text { Lisi not like this CLAS } & \text { book } \\ \text { b. * } & \text { ZHE BEN SHU Lisi } & \text { bu } & \text { xihuan } \\ & & \text { this } & \text { CLAS book } & \text { Lisi } & \text { not like } & \text { like } \\ & & \text { 'Lisi does not like THIS BOOK' } & & \end{array}$

(Badan 2015: 28(10))

While lian-focus is not directly relevant to our discussion, the contrast in (76) supports the parallel between focus and wh-elements that I have proposed in this paper: in a language with an active focus feature in the LLP and no requirement for MOVE, such as present-day Chinese, one does not expect total focus fronting into the HLP to be possible (at least not the one associated with contrastive stress), nor 
low fronting of the eastern Trevisan type. In (77) and (78), I propose a comparison between present-day Chinese and present-day eastern Trevisan low focalisations.

(77)
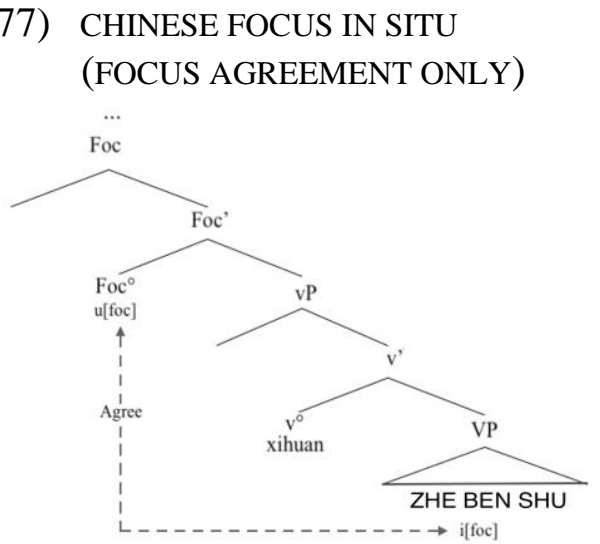

(78) TREVISAN LOW-MOVED FOCUS (AGREE+MOVE)

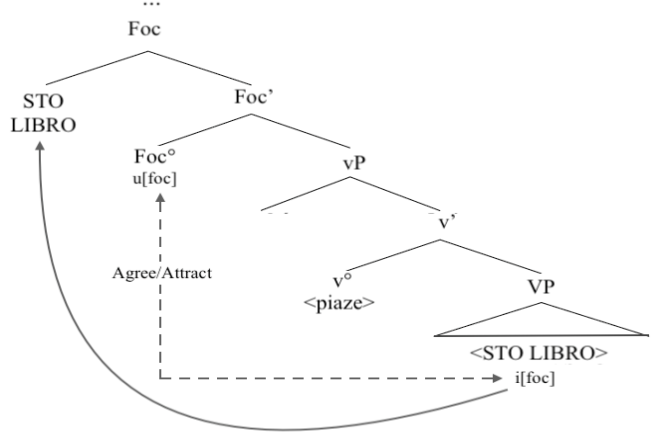

My claim is that the LLP, and more precisely Foc, is the structural locus where Chinese encodes a syntactic [focus]-feature, i.e., one responsible for prosodicallymarked in situ focalisations such as the ones in (76), as opposed to focalisations by means of adverbs such as 'only' in (75). When it comes to prosodically-marked focus and the distribution of wh-elements in answer-seeking interrogatives, presentday Chinese is an eastern Trevisan-style language, minus the requirement for MOVE.

Conveniently, Aldridge argued that the same 'clause-medial' position targeted by wh-elements in Archaic Chinese is also targeted by foci, as in (79): ${ }^{29 ; 30}$

\begin{tabular}{|c|c|c|c|c|c|c|}
\hline a. 吾 & 斯 & 之 & 末 & 能 & 信。 & (Archaic Chinese) \\
\hline $\mathrm{Wu}$ & SI & zhi & wei & neng & & \\
\hline I & this & $3 . \mathrm{Obj}$ & not.yet & can & be.confident & \\
\hline 'I ca & not & yet be co & afident in & THIS' & & \\
\hline b. 彼 & 唯 & 人 & $\overrightarrow{\overline{\bar{~}}}$ & 之 & 聞。 & \\
\hline $\mathrm{Be}$ & wei & REN & $\mathrm{YAN}_{\mathrm{i}}$ & zhi & wu [ wen & $\ldots$ \\
\hline it & only & human & voice & $3 . \mathrm{Obj}$ & hate hear & \\
\hline
\end{tabular}

(adapted from Aldridge 2010: 48(59))

Aldridge explained that the focused constituents of Archaic Chinese had to be resumed by a pronoun, typically the $3 \mathrm{P}$ object pronoun $z h i$, as in (79), the demonstrative $s h i$, or a particle such as wei 'only/even'. As previously pointed out by Wei (1999), Aldridge claimed that focus movement targets a position above

29 A reviewer asks how, in the absence of a context, we can be sure that $s i$ 'this' in (79a) is focalised: Chinese being a topic-comment language, a topicalisation of the subject and $s i$ would be unsurprising. The characterisation of (79a) is attributed to Wei (1999: 281). According to the author, si was a productive focus-marking particle for "objects and complements" in the pre-Qin period (before $211 \mathrm{BC}$ ). A reviewer suggests that the movement of ren yan in (79b) could be triggered by wei ('only'). I believe that this analysis is right, yet it does not impair my argument: the movement in (79b) is low peripheral, as the focus is preceded by the subject in the canonical position. Cf. (75), where a lian-focus is fronted into the HLP. 
negation, as in (79a), and can take place across a non-finite clause boundary, as in (79b). These distributional properties further support the proposed parallel with whmovement, as illustrated in the examples in (80) and (81).

(80) 何城不克?

HE CHENG bu ke?

what city not conquer

'WHAT city would (you) not conquer?'

(Archaic Chinese)

(Aldridge 2009: 9(8))

(81)

$\begin{array}{llll}\text { a. 公 誰 欲 } & \text { (Archaic Chinese) } \\ \text { Gong SHEI yu [ yu _i ] } ? & \\ \text { you who want give } & \end{array}$

b. 公 誰 欲 相?

Gong SHEI $I_{i}$ yu [ xiang _ i $\left.^{-}\right]$?

you who want appoint

'WHO do you want to appoint (as prime minister)?'

(Aldridge 2009: 11(12))

For Aldridge, a subject/object asymmetry is observed in Archaic Chinese, both with foci and with wh-elements. Conversely from what was seen in (79) for objects, a focused subject is not resumed by a pronoun, as in (82). The focused subject also appears to be able to precede adverbs like $d u$, ('alone'), as in ( $82 \mathrm{~b}$ ):
a. 唯 仁 者 能好人, 能惡 人。
Wei ren zhe neng hao ren, neng wu ren only virtuous Det can like person can dislike person
'Only one who is virtuous is capable of liking or disliking someone.'
b. [...] 唯 孫 叔敖 獨 在。
[...] wei Sun Shu-ao du zai only Sun Shu-ao alone remain
'Only [the land of] Sun Shu-ao remained.'
Archaic Chinese (adapted from Aldridge 2010: 48-49(60))

In a similar fashion, subject wh-words can precede $d u$, while object wh-words must follow $d u$. Wei (1999) argued that non-subject wh-elements surface lower than the subject and also lower than certain adverbials, such as the modal jiang, as in (83a); Aldridge observed the same pattern also with $d u$, as in (83b).
a. 我將何求?
Wo jiang HE qiu?
I will what ask.for
'WHAT will I ask for?'

$\begin{array}{llllllll}\text { b. 先生 獨 } & \text { 何 } & \text { 以 } & \text { 說 } & \text { 吾 } & \text { 君 乎? } \\ \text { Xiansheng du } & \text { HE } & \text { yi } & \text { yue } & \text { wu } & \text { jun hu? }\end{array}$

(Archaic Chinese) 
sir(you) alone what with please my lord Q 'HOW were you alone able to please my lord?'

(Aldridge 2010: 16(19))

Note that in both cases in (83), the referential subject precedes the adverbs jiang and $d u$. Importantly, a wh-subject also precedes these adverbs, as in (84):
a. 誰將治之?
SHEI jiang zhi zhi?
who will govern them
'WHO will govern them?'
b. 誰獨 且 無手?
SHEI du qie wu shi hu?
who alone then not.have standard Q

'WHO alone, then, does not have standards?' (Aldridge 2010: 20(17))

The examples in (83) and (84) were used by Aldridge to show that subject and non-subject wh-words surface in different positions which, she claimed, excludes a high movement analysis: if the internal-merge position for wh-elements was located higher than IP, then all wh-phrases should be able to surface higher than jiang or $d u$, contrary to fact. Conversely, the low movement analysis does account for the observed asymmetry: non-subject wh-phrases move to the LLP, while whsubjects need to be in the canonical subject position, as in (85):

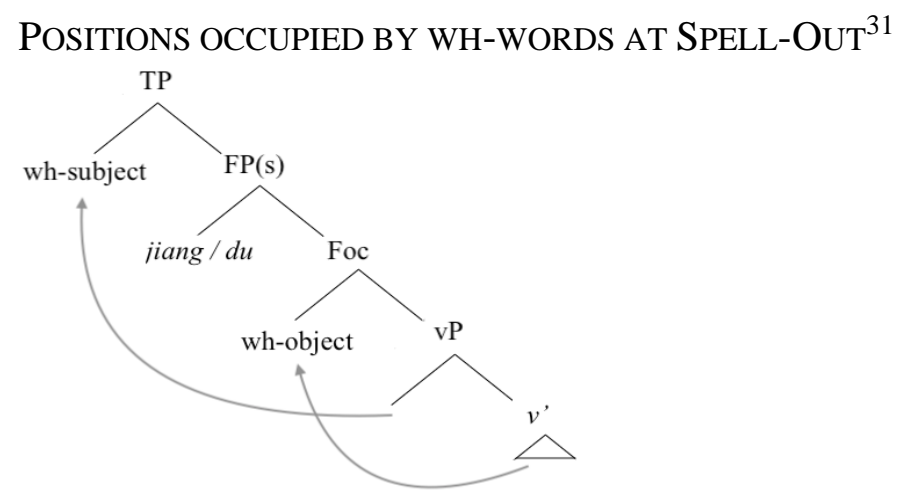

Aldridge proposed that wh-subjects "are required to move out of $v \mathrm{P}$ as a result of the EPP feature on $T$, which must be checked for the derivation to converge" (Aldridge 2010: 20). That there is an asymmetry between subject and non-subject wh-elements is also clear in eastern Trevisan which, like many NIDs, can virtually only construe wh-questions bearing on the subject by means of a cleft: only the subject of unaccusatives can stay in situ, suggesting that the observed limitations are not directly due to subjecthood but to structural considerations (Bonan 2019).

It is noteworthy that the wh-words of present-day Chinese are indefinites or polarity items and have no quantificational force of their own; for instance, when a wh-word is in the scope of a yes/no question particle, such as $m a$ in (86), an existential interpretation obtains:

31 I put both jiang and $d u$ in SpecFP to avoid taking a stand on their relative order. 
(86) $\mathrm{Ni}$ mai-le sheme ma?
you buy-ASP what Q
'Did you buy something?'

(Chinese)

(Aldridge 2009: 2(1))

In line with Aboh \& Pfau's (2011) discussion of the cross-linguistic inability of whelements to contribute to clause-typing and Cable (2010), the existence of a silent Q-particle in the wh-interrogatives of Chinese also ought to be posited, which moves into the HLP to check the [q]-feature in Rizzi's (1997) Focus. A characterisation of Chinese as either Q-projecting or Q-adjoining is in order yet goes beyond the scope of this article. For now, simply note that the fact that the lowmovement of wh-elements in Archaic Chinese stranded the preposition in the external-merge site, as in (87), suggests that this language might be one in which the Q-particle is able to intervene between a selector and its complement (like the $\mathrm{P}$ and $y u$ and the wh-element SHEI here), as tentatively sketched in (88).

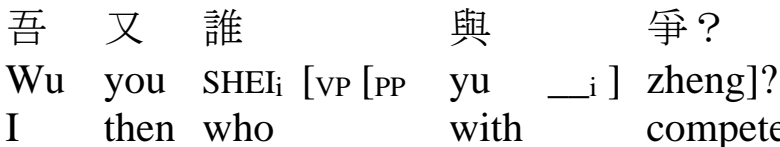

$$
\begin{aligned}
& \text { 'Then wHO would we compete with?' }
\end{aligned}
$$

(Archaic Chinese)

(Aldridge 2009: 14(14))
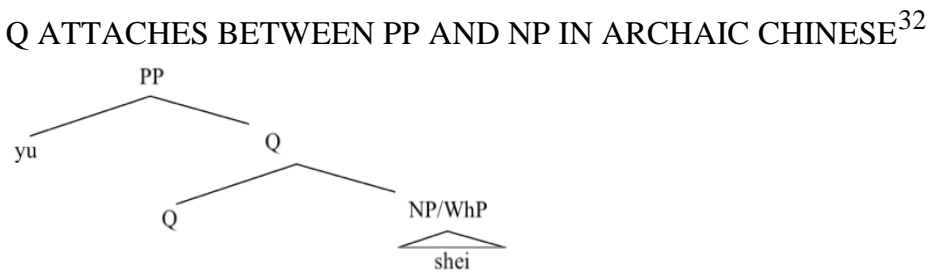

If the Q-particle was unable to appear between a PP and its complement NP, and rather needed to adjoin to/select the whole PP, the felicity of preposition stranding instances such as that in (87) would be unexpected. A prediction of (88), to be verified, is that Archaic Chinese should also allow possessor extraction and Dextraction in the sense of Cable's (2010: 57(107)) 'QP-intervention condition', which the language does not seem to violate. I leave the investigation of the technicalities related to the relationship between the Q-particle and the wh-element in the answer-seeking wh-questions of Chinese for further work.

\section{A new theory of northern Italian wh-in situ}

In Bonan (2019) I claimed that to understand the interrogative syntax of wh-in situ languages the status of seven variables needs to be assessed. These are as follows:

i. possibility to have non-D-linked wh-elements clause-internally;

ii. possibility to have D-linked wh-elements clause-internally; 
iii. requirement for clause-internal wh-elements to occupy the rightmost edge of the clause ('sentence-final requirement' in the sense of Etxepare \& Uribe-Etxebarria 2005);

iv. presence of low movement of clause-internal wh-elements;

v. availability of long construals;

vi. availability of wh-in situ in indirect questions;

vii. availability of clause-internal wh-elements within islands to extraction.

A special combination of variables (i) and (ii), which is only attested in Bellunese as described in Munaro (1999), will henceforth be referred to as the ' $D$-linked/nonD-linked asymmetry'. ${ }^{33}$ This refers to the possibility for wh-words to only surface clause-internally, coupled to the requirement for wh-phrases to surface totally fronted into the HLP. As for the status of SCLI in constructions with a clause-internal wh-element, it must be noted that this phenomenon has often, yet wrongly, been paid a great amount of attention in the northern Italian literature. French is the only known language in which the availability of SCLI is not orthogonal to the surface position of the wh-element (Manzini \& Savoia 2005, Bonan 2017), therefore its status does not need to be assessed in any other wh-in situ language. As for French, in which the phenomenon of SCLI is a by-product of the presence of a residual v2environment in the HLP, in which all PHI-features fail to be passed to T in answerseeking interrogatives (Roberts 2007;2010), the fact that wh-in situ is excluded both in the presence of SCLI, as seen in (2), and the interrogative marker est-ce, /es/, as in (89), signals that in this language clause-internal wh-elements at Spell-Out are a consequence of constructions in which the HLP is not active before interpretation:

$$
\begin{aligned}
& \text { a. QUI est-ce qui te } l \text { l'a dit? } \\
& \text { who est-ce that to.you it=has said } \\
& \text { 'WHO told you this?' } \\
& \text { b. * Est-ce que te } \\
& \text { est-ce that to.you it=has said who }
\end{aligned}
$$

(French)

While the question of how French wh-in situ is derived still deserves attention to be fully understood, I believe that the ungrammaticality of the constructions in (2) and (89) argues that French wh-in situ is of a different type with respect to that of the other Romance languages discussed in this paper. These phenomena, which could be a by-product of an impoverishment of the functional peripheries due to the Germanic influence that the language endured starting from the $3^{\text {rd }}$ century $C E$, suggest that the outlier of Romance is French, not Bellunese.

\subsection{A mixed picture of focus-agreement and focus movement}

Looking at the settings (positive or negative) of the variables in (i) to (vii), as in TABLE 1, it is possible to observe that all varieties attested and described in Manzini \& Savoia (2005) can be treated on a par with eastern Trevisan. Two notable exceptions are the status of the low movement of wh-elements, which, as Maria

33 I use the term 'D-linked/non-D-linked asymmetry' as a descriptive generalisation; please be aware that some non-lexically-restricted wh-elements can in fact be Dlinked (Bellunese qual/quant, French lequel, etc.). 
Rita Manzini pointed out (pc.), was not assessed in hers and Savoia's (2005) corpus (whence the label NA, 'non attested'); and the unavailability of wh-in situ in the indirect questions of some varieties.

Table 1. Distribution of wh-in situ in NIDs

\begin{tabular}{|c|c|c|c|c|}
\hline & & TREVISAN & $\begin{array}{c}\text { LOMBARD/VENETAN } \\
\text { (MANZINI \& } \\
\text { SAVOIA) }\end{array}$ & $\begin{array}{c}\text { BELLUNESE } \\
\text { (POLETTO \& } \\
\text { POLLOCK) }\end{array}$ \\
\hline (I) & WH-WORDS IN SITU & + & + & + \\
\hline (II) & WH-PHRASES IN SITU & + & + & - \\
\hline (III) & $\begin{array}{c}\text { SENTENCE-FINAL } \\
\text { REQUIREMENT }\end{array}$ & - & - & + \\
\hline (IV) & LOW MOVEMENT & + & NA & - \\
\hline (V) & LONG CONSTRUALS & + & + & + \\
\hline (VI) & INDIRECT WH-IN SITU & + & $+/-$ & - \\
\hline (VII) & IN-ISLAND WH-IN SITU & + & + & - \\
\hline
\end{tabular}

It must be noted that, contra Bonan (2019), the status of wh-in situ in indirect questions is in fact accessory in the determination of the type of wh-in situ. At least in Romance, its availability depends solely on the presence of wh-doubling, as in (90), or of a special complementiser such as that of eastern Trevisan in (91):
a. so
'mia 'kome
i fa
ko'me
know 1 PS NEG how they do how
'I don't how they do (what they're doing)'

(Strozzense)

b. me se do'mande 'koza i 'fa ko'ze

to.me they ask what they do what

'I'm asked what they're doing / they do'

(Manzini \& Savoia 2005: 592-3(156))

(91) a. Me domando [ se te gà magnà cossa ] REFL ask 1 PS if $=$ you $=$ have eaten what

'I wonder what you ate'

b. A se domanda [ se 1 vegnarà cuando $]$ she $=$ REFL asks if $=$ he $=$ come $\mathrm{FUT}$ when

'She wonders when he's going to come'

All varieties that do not have either strategy require systematic fronting of whelements into the embedded HLP. This property follows from a canonical 'matrix/embedded asymmetry' whereby clause typing must be done by a phonetically-realised element in embedded environments.

Going back to Table 1, in Bellunese the setting of most variables is an exception to the general picture. First, while the language allows wh-words to surface clause-internally, it disallows wh-phrases in that position, which are fronted to a clause-initial position that has been claimed incompatible with non-D-linked elements, as in (92) and (93): 
(92) a. A-tu parecià CHE?

have $=$ you prepared what

(Bellunese)

'WHAT did you prepare?'

b. * CHE à-tu parecià?

what have $=$ you prepared

(Munaro 1999: 50(1.56))

(93) a.
CHE VESTITO à-tu sièlt?
what dress have=you chosen
'WHICH DRESS did you choose?'
b. * A-tu sièlt CHE VESTITO?
have $=$ you chosen what dress

(Bellunese)

(Munaro 1999: 14(1.2))

Bellunese also displays a 'sentence-final requirement' à la Etxepare \& UribeEtxebaria (2005): in this variety, the clause-internal wh-word has to occupy the rightmost position in the clause, with everything that follows somehow dislocated from the core. This property, illustrated in (94), has been used in the remnant-IP to claim that the wh-word of these constructions is not in its external-merge position:

(94) a. Al ghe ha dat al libro a so fardel (Bellunese) he DAT has given the book to his brother

'He gave the book to his brother'

b. * Ghe ha-lo dat CHE a so fradel?

DAT has=he given what to his brother

'WHAT has he given to his brother?'

c. Ghe ha-lo dat CHE, a so fradel?

DAT has=he given what \# to his brother

(Poletto \& Pollock 2015: 139(2))

In addition to this, while Bellunese does not appear to have low movement of clause-internal wh-elements, it does have long construals, as discussed in §3.1. Conversely, the language notoriously excludes wh-in situ both from indirect questions, as in (95), and from syntactic islands, as in (96):
a. No so
CHE che l'a
NEG know1Ps
what
'I don't know WHAT he bought'
b. * No so (che) l'ha comprà CHE NEG know 1 PS (that) he=has bought what

(Munaro 1999: 69(1.93))

(96) a. * Te à-li dit che [ $\mathrm{i}$ clienti de $\mathrm{CHI}]$ no i-à pagà? you have=they said that the clients of who NEG they=have paid 'WHOSE clients did they tell you didn't pay?'

b. * Pensi-tu che [ partir QUANDO ] saria sbaglià? think=you that leave when would.be wrong 'WHEN do you think it would be wrong to leave?' 
The Bellunese properties in (94-99) really do constitute an exception to bothe northern Italian and Asian wh-in situ. Indeed, as suggested in TABLE 1, Chinese and Japanese pattern with eastern Trevisan and Manzini \& Savoia's (2005) varieties today. Observed exceptions are the unavailability of WH-TO-FOC, and the felicity of wh-in situ in indirect questions in the absence of wh-doubling or of a special embedded COMP in Chinese: the availability of either element is a conditio sine qua non for the felicity of indirect wh-in situ in Romance (\$5.2). I illustrate the setting of the variables in Chinese and Japanese in TABLE 2 and 3, respectively:

Table 2. Distribution of wh-in situ in present-day Chinese

\begin{tabular}{|c|c|c|}
\hline VARIABLE & \pm & REPRESENTATIVE EXAMPLE \\
\hline (I) & + & 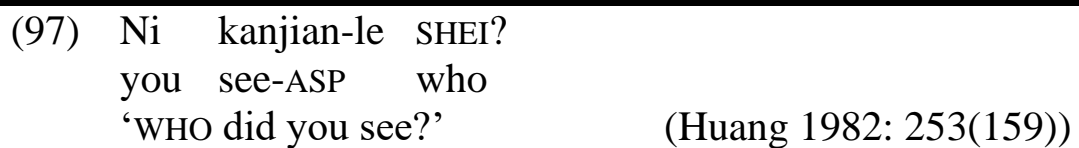 \\
\hline (II) & + & $\begin{array}{l}\text { (98) Měi-gè nánshēng dōu xȟhuān NǍ-BĚN SHŪ? } \\
\text { every-CL boy all like which-CL book } \\
\text { 'WHICH BOOK does every boy like?' } \\
\text { (Pan 2014: 6(12)) }\end{array}$ \\
\hline (III) & - & $\begin{array}{l}\text { (99) } \mathrm{Ni} \text { zai nar gongzuo? } \\
\text { you where work } \\
\text { 'Where do you work?' }\end{array}$ \\
\hline (IV) & - & NA \\
\hline (V) & + & $\begin{array}{l}\text { (100) Huángróng xiāngxìn [ Guōjìng maǐ-le SHÉNME]? } \\
\text { Huangrong believe Guojing buy-PERF what } \\
\text { 'WHAT does Huangrong believe (that) Guojing bought?' } \\
\text { (Cheng \& Bayer 2015: 4(6)) }\end{array}$ \\
\hline$(\mathrm{VI})$ & + & $\begin{array}{l}\text { (101) Botong xiang-zhidao [Hufei mai-le SHENME ] } \\
\text { Botong want-know Hufei buy-PERF what } \\
\text { 'Botong wants to know WHAT Hufei bought' } \\
\text { (Cheng 2003: 103(3b)) }\end{array}$ \\
\hline (VII) & + & $\begin{array}{l}\text { (102) Nǐ xiăng-zhīdào [wǒ wèishénme maǐ SHÉNME ]? } \\
\text { you wonder I why buy what } \\
\text { 'What is } x \text { such that you wonder WHY I bought } x \text { ?' } \\
\text { (Cheng \& Bayer 2015: 5(14a)) } \\
\text { (103) Zhāngsān [[yīnwèi SHÉI méiyǒu lái ]] hěn shēngqì } \\
\text { Zhangsan because who not.have come very angry } \\
\text { 'WHO is } x \text { such that Zhangsan got angry because } x \text { didn't } \\
\text { come?' } \\
\text { (Cheng \& Bayer 2015: 5(14b)) }\end{array}$ \\
\hline
\end{tabular}

Table 3. Distribution of wh-in situ in present-day Japanese 


\begin{tabular}{|c|c|c|}
\hline VARIABLE & \pm & REPRESENTATIVE EXAMPLE \\
\hline (I) & + & $\begin{array}{l}\text { (104) Calvin-ga NANI-o mottekita-ndesu-ka. } \\
\text { Calvin-N what-A brought-POLITE-Q } \\
\text { 'WHAT did Calvin bring?' } \\
\text { (Ueno \& Kluender 2003: 492(2)) }\end{array}$ \\
\hline (II) & + & $\begin{array}{llll}\text { (105) DONA KURUMA-ga hoshii } & \text { dese } & \text { ka? } \\
\text { which car-NOM } & \text { want } & \text { COP-POLITE } & \text { Q } \\
\text { 'WHICH CAR do you want?' } & & \\
& & & \text { (Hiromune Oda, p.c.) }\end{array}$ \\
\hline (III) & - & (any example in this table) \\
\hline (IV) & - & NA \\
\hline (V) & + & $\begin{array}{l}\text { (106) [ Hobbes-wa [ Calvin-ga NANI-o mottekita-to ] } \\
\text { Hobbes-T Calvin-N what-A brought-that } \\
\text { itta-ndesu-ka]. } \\
\text { said-POLITE-Q } \\
\text { 'WHAT did Hobbes say Calvin brought?' } \\
\text { (Ueno \& Kluender 2003: 493(3b)) }\end{array}$ \\
\hline$(\mathrm{VI})$ & + & $\begin{array}{l}\text { (107) John-wa [ Mary-ga DOKO-ni ik-u ka ] ei-ta. } \\
\text { John-T Mary-N where-to go-PRES Q ask-PAST } \\
\text { 'John asked wHERE Mary was going' } \\
\text { (Lit: 'John asked Mary was going WHERE') } \\
\text { (adapted from Yoshida \& Yoshida 1996: 258(4)) }\end{array}$ \\
\hline (VII) & + & $\begin{array}{l}\text { (108) Mary-wa [NP [IP DARE-ga tsukutta ] sushi ]-o } \\
\text { Mary-TOP who-NOM made sushi -ACC } \\
\text { tabeta no? } \\
\text { ate Q } \\
\text { 'WHO is } x \text {, such as } x \text { is a person, and Mary ate sushi that } x \\
\text { made?' (Lit: 'Mary eat sushi [that WHO made]?') } \\
\text { (adapted from Kayama 2005: 1(1)) } \\
\text { (109) [NP [IP John-ga ITSU katta ] hon ]-ga } \\
\text { John-NOM when bought book -NOM } \\
\text { nakunatta no? } \\
\text { disappeared Q } \\
\text { 'For which } x, x \text { time, the book [that John bought } x \text { ] } \\
\text { disappeared?' } \\
\text { (Lit: 'The book [that John bought WHEN] disappeared?') } \\
\text { (adapted from Kayama 2005: 2(4b)) }\end{array}$ \\
\hline
\end{tabular}

With this in mind, I now outline my understanding of how WH-TO-FOC works synchronically and diachronically in the languages that 'scatter' [focus] in the LLP, then come back to the Bellunese data and their analysis in $§ 5.2$.

\subsubsection{Types of wh-in situ and Parameters}

The synchronic data presented in Manzini \& Savoia (2005), coupled with the Chinese and Japanese data in TABLES 2-3, and the diachronic evidence discussed in $\S 4.2$, suggest that all varieties under consideration derive wh-in situ by first 
checking a syntactically active [focus]-feature in the LLP. Among these, some require AGREE alone, while others require AGREE+MOVE. Only the latter have low focus movement of the eastern Trevisan type. The existence of mixed 'AGREE alone/AGREE+MOVE' systems is to be expected. The picture is as outlined in (110):

(110) TYPES OF WH-IN SITU

TYPE I: FOCUS AGREEMENT + FOCUS MOVEMENT

(= requirement for AGREE+MOVE)

eastern Trevisan, Archaic Chinese (Warring states), Old Japanese (Nara period), some Venetan and Lombard varieties as described in Manzini \& Savoia (2005), etc.

TYPE II: MIXED SYSTEM

(=movement parameter not yet set)

Archaic Chinese (beginning of the Han Dynasty), Old Japanese (Heian period), some Venetan and Lombard varieties, etc.

TYPE III: FOCUS AGREEMENT ALONE (requirement for mere AGREE)

Present day Chinese, present-day Japanese, some Venetan and Lombard varieties, etc.

Based on my diachronic discussion in $\S 4.2$, I wish to suggest that, in the languages under investigation in this paper, the diachronic evolution of answerseeking interrogatives follows the path suggested in (111):

\section{(111) EVOLUTION OF ANSWER-SEEKING INTERROGATIVES ${ }^{34}$}

TYPE I > TYPE II > TYPE III

The pattern in (111) suggests a tendency of derivational simplification: what can be done via AGREE alone eventually wins out. This can be formulated as in (112):

(112) DERIVATIONAL SIMPLICITY PRINCIPLE ${ }^{35}$

Whenever possible, prefer AGREE over AGREE+MOVE.

The status of the low-peripheral [focus]-feature needs assessing in all wh-in situ varieties, especially those that derive wh-in situ via covert QP-movement. Is QPfronting done passing through Foc in the LLP or are some languages able to skip this intermediate position? Even more importantly, is the WH-TO-FOC step also

34 Dadan (2019) suggested another possible pattern of evolution, whose existence I predicted in Bonan (2021): the pattern from total fronting into the HLP to real whin situ, i.e., from overt to covert QP-movement. According to him, this pattern is observed in the diachrony of Sinhala. I believe this possibility should also be assessed in the transition from literary French to Contemporary Spoken French.

35 Dadan (2019) proposed an explanation for the changes in interrogative syntax that I analyse, from the perspective of labelling (Chomsky 2013). Accordingly, the pressures imposed by the Labelling Algorithm to maximise head-phrase $\{\mathrm{H}, \mathrm{YP}\}$ configurations and minimise the $\{\mathrm{XP}, \mathrm{YP}\}$ as well as $\{\mathrm{X}, \mathrm{Y}\}$ mergers make the latter ones prone to loss. While Dadan and I approach the same phenomena in different ways, we both conclude that the evolution goes from overt to no movement. 
involved in the derivation of eastern Trevisan total fronting, i.e., is WH-TO-FOC what has been referred to as successive-cyclic movement through the edge of the $v \mathrm{P}$ phase (Chomsky 1973;1995)? The cyclicity of wh-movement has been argued for in works on wh-agreement, interrogative inversion/prosodic phenomena, and pronunciation of intermediate copies (Torrego 1984, McDaniel 1986;1989, McCloskey 2001;2002, Willis 2000, van Urk \& Richards 2015, Bocci et al. 2020, a.o.). While phase theory teaches us that anything that goes to the HLP must stop at $\nu \mathrm{P}$, my discussion suggests that this intermediate 'stop' can take place at different heights: in SpecvP for some languages, in FocP in languages like eastern Trevisan. These are some of the questions that will have to be investigated in further work.

I now wish to suggest a reformulation of Cable's Parameters as in (113):

\section{(113) $\pm \mathrm{QP}$ [formerly PROJECTION PARAMETER]}

In Q-adjunction languages, Q adjoins to its sister and their mother is of the same category as the sister (in most cases, a Wh-projection). In Q-projection languages, Q takes its sister as complement, and so the node minimally dominating the $\mathrm{Q}$ and its sister is a QP. Some languages have both Qadjunction and Q-projection.

\section{土overtQ [Q-PRONUNCIATION PARAMETER]:}

In some languages, like Tlingit, the Q-particle has phonological content. In other languages, the Q-particle is phonologically null.

\section{士overtM [Q-MOVEMENT PARAMETER]:}

In overt Q-movement languages, the highest syntactic copy of a Q-particle is pronounced. In covert Q-movement languages, the lowest syntactic copy of a Q-particle is pronounced. [...] The setting of this parameter depends on the requirement for AGREE only vS AGREE+MOVE in the relevant projection.

In Bonan (2021b), as an extension of my first formulation of WH-TO-FOC, I also proposed the existence of a fourth parameter, as in (114):

(114) \pm bundle: 'INTERROGATIVE FEATURES PARAMETER': bundling vs. scattering There exist languages in which all features related to interrogative whmovement are bundled in the HLP, and languages in which these features are scattered between the HLP and the LLP.

The \pm bundle parameter is based on Miyagawa's (2001) claim that languages that allow for wh-in situ check [+WH] IP-internally and only [+Q] in the HLP. In the spirit of that investigation, in Bonan (2021b) I offered an understanding of the differences between languages like eastern Trevisan and Standard Italian in terms of a parametrised choice between interrogative 'feature scattering' and 'feature bundling' ${ }^{36}$ Here, I have not discussed the matter of the structural loci where the two features related to interrogative wh-movement are encoded in the functional spine because I have only dealt with 'scattering' languages.

36 Cf. Badan \& Crocco (2021) for a recent investigation of wh-in situ in Italian, a strategy often considered unavailable in the standard variety. Accordingly, clauseinternal wh-element are felicitous in Italian and move to the LLP (it is therefore possible the language ought to be understood as a 'feature scattering' one). 


\subsection{Rethinking Bellunese}

I have mentioned that Munaro (1999) took in situ wh-words to remain clauseinternally in Bellunese, and posited the presence of an operator that moved overtly from the middle-field to the HLP to determine the scope of the wh-word. In Bonan (2021), I suggested that an extension of the theory of WH-TO-FOC to the morphosyntax of Bellunese is desirable: Munaro's (1999) analysis was on the right track, and his silent operator was a Q-particle à la Cable (2010) ante litteram. Nonetheless, some language-specific adaptations will of course be required.

Superficially, Bellunese as in TABLE 1 might seem unable to fit into any of the TYPES that I have singled out here. However, to posit that this language is somehow special and derives wh-in situ left-peripherally, as in the remnant-IP movement analysis, seems empirically problematic given the possibility, reported by Munaro (1999), for this variety to have long construals. What is more, to posit that Bellunese is an outlier with respect to its interrogative syntax would imply the existence of too big a typological gap between this variety and all closely-related Romance varieties attested in northern Italy. Indeed, contra Bonan (2017), while the assumption that Bellunese could be typologically distant from the languages of Asia is not theoretically implausible, it is undesirable to posit the existence of another TYPE within the Romance domain. This is relevant in light of Chomsky's (2001) Uniformity Principle reported in (115):

\section{UNIFORMITY PRINCIPLE (Chomsky 2001: 2)}

In the absence of compelling evidence to the contrary, assume languages to be uniform, with variety restricted to easily detectable properties of utterances.

In line with my observations in $\$ 3$ and with Occam's razor, whereby of two explanations that account for all the facts, the simpler one is more likely to be correct, in what follows I propose an understanding of the interrogative syntax of Bellunese that follows from my theory of WH-TO-FOC.

An asymmetrical distribution of D-linked and non-D-linked wh-elements is not attested in any NID or more generally any Romance variety other than Bellunese. Examples from Lombard Grumellese are reported in (116): ${ }^{37}$
a. in ke poht 1 e:t kom'pra:t? in what place it have2PS bought
'Where did you buy it?'
b. 1 e:t kom'pra:t in ke poht? it have 2 PS bought in what place
c. ke liber e:t le'zit?
what book have 2 Ps read
'Which book did you read?'
d. e:t le'zit ke liber?
have $_{2 \mathrm{PS}}$ read what book

\footnotetext{
37 For a similar discussion applied to the Romance varieties spoken outside of Italy, the reader will refer to Bonan (2021: 183-192).
} 
The fact that in some optional in situ languages not all wh-elements can surface either clause-internally or sentence-initially can be explained as a consequence of three properties. First, it is widely acknowledged that special, inherent properties of wh-elements influence their distribution. For instance, crosslinguistically why-words are understood to be externally-merged directly in the HLP, and thus inconsistent clause-internally (Rizzi 2001, Stepanov \& Tsai 2009, Shlonsky \& Soare 2012; but see also Bonan \& Shlonsky 2021 on the different distributional properties of the two why-words of eastern Trevisan, parké and parkossa). Furthermore, in intermediate stages of evolution, the mechanisms of Qprojection and Q-adjunction can be expected to not apply to all types of wh-element homogeneously; in Bellunese, for example, Q-adjunction has been generalised to wh-words, while in eastern Trevisan it can apply to all wh-elements. ${ }^{38}$

Bellunese has two pronominal wh-words that alternate between the low and the high position, qual ('which one') and quant ('how much'), as in (118) and (119):
a. QUAL à-tu sièlt?
which.one have=you chosen
'WHICH ONE did you choose?'
$\begin{array}{lll}\text { b. À-tu } & \text { sièlt } & \text { QUAL? } \\ \text { have=you } & \text { chosen } & \text { which.one }\end{array}$

(Bellunese)

(Munaro 1995: 72(5))
a. QUANT ghen'à-tu magnà? how.much of.it=have=you eaten 'HOW MUCH of it did you eat?'
b. Ghen'à-tu magnà QUANT?
of.it=have=you eaten how.much

(Bellunese)

(Munaro 1995: 73(10))

Quant and qual are D-linked but not lexically restricted. It is thus plausible to think that the $[+\mathrm{N}]$ feature is, at present, incompatible with Q-adjunction in the language.

It must also be noted that the [ \pm discourse-linkedness] of wh-elements is independently known to influence their distribution. In Standard Italian, for instance, it has been noted that wh-phrases and wh-words do not target the same projection in the HLP. Observe (120) and (121): (120) a. *
Dove Gianni
where gianni ha messo le where gianni has put the keys
le chiavi?
(Standard Italian)

38 In passing, note thet the contrast in (i), whereby Trevisan ke can only surface clause-internally, suggests that this language is moving towards a generalisation of Q-adjunction (it is the only wh-element that displays this distribution).
(i) a. gatu fato ke?
have=you done what 'What did you do?'
b. * ke gatu fato?
what have=you done 
'Where did Gianni put the keys?'
b. In che cassetto Gianni ha
messo le chiavi?
in what drawer Gianni has put the keys
'In which drawer did Gianni put the keys?'

c. Perché Gianni ha messo le chiavi nel cassetto? why Gianni has put the keys in.the drawer 'Why did Gianni put the keys in the drawer?'

(Rizzi 2018: 350-1(19-21))

(121)a. * Dove LE CHIAVI hai messo, non le sigarette? where the keys have2Ps put NEG the cigarettes Lit: 'Where THE KEYS you put, not the cigarettes?'

b. ? In che cassetto LE CHIAVI hai messo, non le sigarette? in what drawer the keys have put NEG the cigarettes Lit: 'In which drawer THE KEYS you put, not the cigarettes?'

c. Perché LECHIAVI hai messo nel cassetto, non le sigarette? why the keys have put in.the drawer NEG the cigarettes Lit: 'Why THE KEYS you put in the drawer, not the cigarettes?'

Standard Italian (adapted from Rizzi 2018: 351(23))

In (120), the wh-word dove ('where') is incompatible with an immediately following lexical subject, contrary to the wh-phrase in che cassetto ('in which drawer'), which resembles the distribution of perché ('why'). Similar behaviours are observed with respect to a contrastively-focused constituent: while wh-words are inconsistent with a following focus, as in (121a), wh-elements and perché are, respectively, marginally and perfectly compatible with it. Following the observation of the contrastive distributions in (120) and (121), Rizzi (2018) proposed that the left-peripheral interrogative projections are those in (122):

\section{) LEFT-PERIPHERAL INTERROGATIVE SITES (Rizzi 2018: 351(22))}

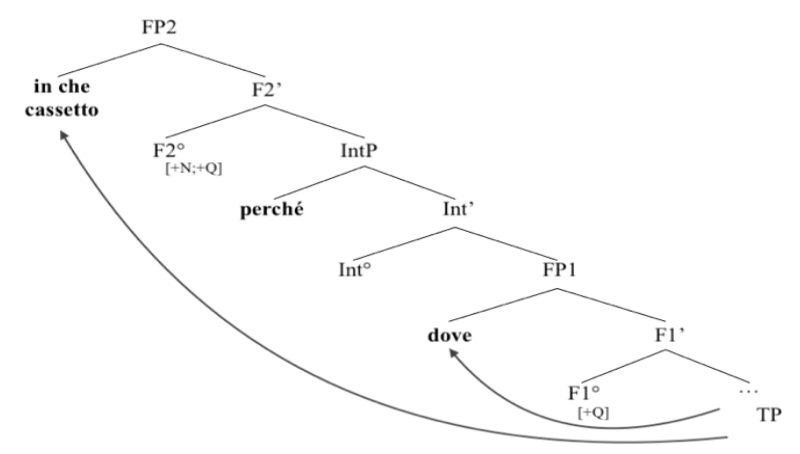

Accordingly, what is commonly understood as a left-peripheral FocusP is actually made up of at least two functional projections surrounding IntP: a higher one which encodes $[+\mathrm{N} ;+\mathrm{Q}]$, and a lower one that encodes merely [Q]. I thus maintain that the non-ordinary distribution of most wh-elements of Bellunese, and more precisely what I have referred to as the 'D-linked/non-D-linked asymmetry', does not per se constitute a problem for an extension of the theory of WH-TO-FOC to this variety.

Another distributional peculiarity of Bellunese that does not seem problematic for an extension of my theory to Bellunese is the so-called 'sentence- 
final requirement' in the sense of Etxepare \& Uribe Etxebarria (2005). This is a property whereby wh-elements (wh-words in the case of Bellunese) need to occupy the rightmost clausal edge, as seen in (94). Munaro et al. have taken the fact that the wh-words of Bellunese have a peculiar distribution whereby anything that follows the clause-internal wh-element needs to be phrased as an independent intonational phrase, as evidence that these are in an internal-merge position, more specifically a high left-peripheral one. However, an analysis in terms of WH-TOFOC, coupled with a PF constraint that requires wh-elements to be in the main-stress position, can explain the Bellunese data in a more economical and typologically coherent way compared to the remnant-IP movement analysis. Crucially, the fact that the possessive within the IO a so fradel ('to his brother') in (123) refers to the the subject of the clause, lo ('he'), suggests that the IO is c-commanded by the rest of the sentence, i.e., not right-dislocated:

$$
\begin{aligned}
& \text { Ghe ha-lo dat CHE, a so fradel? } \\
& \text { DAT has=he given what \# to his brother } \\
& \text { 'WHAT has he given to his brother?' }
\end{aligned}
$$

(Poletto \& Pollock 2015: 139(2))

Following Belletti (2004), the post-focal material in sentences like (123) is compatible with a movement analysis to the low topic position in the LLP, with the wh-word moved into Foc. I sketch this in the diagram in (124):

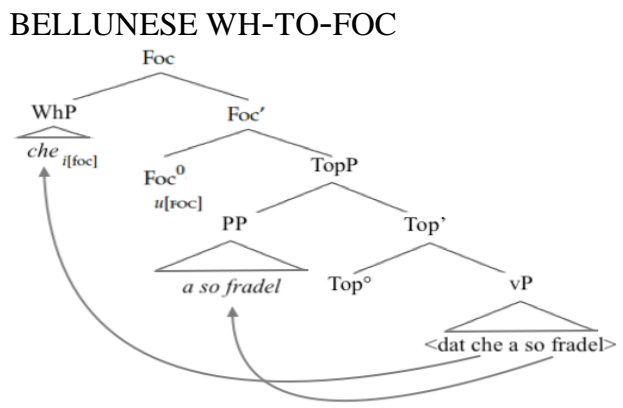

As for the incompatibility of wh-in situ within islands, Cable (2010) himself offers an explanation for languages like Bellunese. Recall from the discussion in $\S 4$ that it is only when the Q-particle is located outside of the island that it is accessible to the matrix HLP, i.e., an agreement relation is established between the HLP and Q, while the matrix HLP bears no syntactic relationship to the wh-operator. Munaro (1999) showed the ungrammaticality of wh-in situ within islands to extraction, as in (96). In contrast, eastern Trevisan in-island wh- is fine, as in (125):

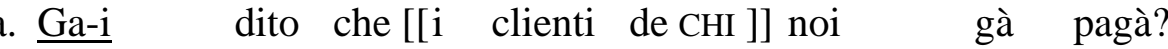 have=they said that the clients of whom NEG=they have paid 'Who is $x, x$ a person, such as they said that the clients of $x$ didn't pay'
b. (Eora,) ga-tu comprà [[ un porsel che peza CUANTO]]? (so) have $=y^{2} u_{28}$ bought a pig that weights how.much 'What is $x, x$ an amount, such as you bought a pig whose weight is $x$ '
c. (Eora,) ze-o partìo [[ sensa saeudar CHI ]], sto giro? (so) is=he left without greeting who this round


'Who is $x, x$ a person, such as he left without greeting $x$ '

In (125), the presence of SCLI suggests that we are dealing with Q-adjunction to the island, like in regular cases of wh-in situ. Interestingly though, massive pied piping is also partially possible in eastern Trevisan, as in (126):

$$
\begin{aligned}
& \text { ? (Eora) }[[\text { un porsel } \\
& \text { che pesa cuanto }]]_{\mathrm{j}} \text { ga-tu }
\end{aligned}
$$

The phenomenon in (126) is referred to as PPPI in Cable (2010), i.e., pied-piping past island. PPPI is a peculiar interrogative configuration done in the presence of the projection of $\mathrm{Q} .{ }^{39}$ Trevisan is a language in which $\mathrm{Q}$ is able to project, therefore the felicity of (126) does not come as a surprise. However, not all QP-fronting languages allow PPPI, as illustrated by the examples in (127):

(127) a. * [DP A fish [CP that is HOW big ]] do you want?

b. * [DP A book [CP that WHO wrote ]] did you buy?

(English)

(Cable 2010: 144(5))

The unavailability of PPPI in Q-projecting languages such as English is explained as a consequence of the availability of 'limited' pied-piping, defined as in (128):

THE NATURE OF LIMITED PIED-PIPING (Cable 2010: 144(14))

If the Q-particle must Agree with the wh-element it c-commands, then a wh-element cannot be dominated in the sister of $\mathrm{Q}$ by islands or lexical categories. Thus limited pied-piping languages are those where $\mathrm{Q} / \mathrm{wh}-$ Agreement must occur.

According to (128), the Q-particle bears an interpretable but unvalued Q-feature $(i \mathrm{Q}[])$ in languages as English, yet probing and agreement cannot apply across islands. Let us now go back to the Bellunese island examples; observe (129):

$$
\begin{aligned}
& \text { * Te piase-lo [[ } \mathrm{i} \text { libri che parla de che }]] \text { ? } \\
& \text { you like }=\text { it the books that speak of what } \\
& \text { 'What is } x, x \text { a topic, you enjoy books about } x \text {, } \\
& \text { Bellunese (adapted from Munaro 1999: 74(1.105)) }
\end{aligned}
$$

While it would be interesting to assess whether structures like (136) become acceptable in the absence of SCLI, the generalised unavailability of in-island wh-in situ in Bellunese can be attributed to the need, in this variety, for Q and the whword to AGREE. I illustrate this in (130):

(130) ILLICIT PIED-PIPING PAST ISLAND IN BELLUNESE

39 In Bonan (2021) I claimed that examples such as the one in (126) are also possible without overt PPPI. Predictably, these instances do not feature SCLI. It is interesting to note that other NIDs with otherwise obligatory SCLI display the same pattern, as Grumellese (Manzini \& Savoia 2005: 587). This fact deserves attention. 


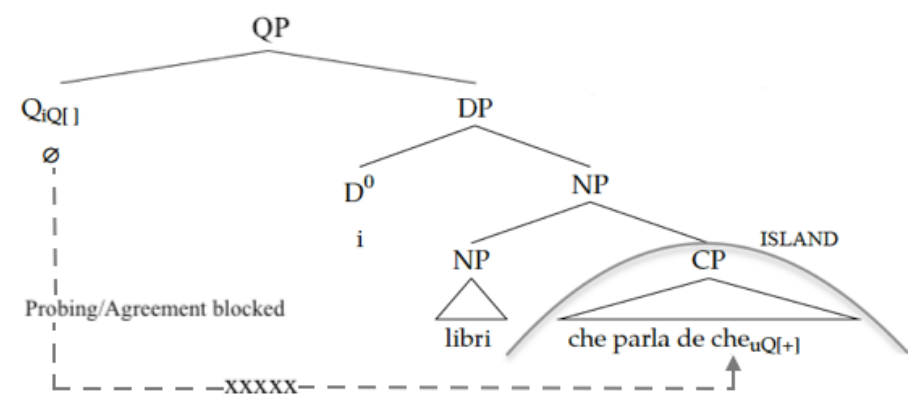

To summarise, the theory of WH-TO-FOC offers a new, economic explanation for the syntax of northern Italian wh-in situ which, contrary to the remnant-IP movement analysis, also applies beyond the Romance domain. Crucially, while I have shown that a derivation à la Munaro et al. does not apply to any NID other than Bellunese, minimal language-specific adaptations are sufficient to extend WH-TOFOC across languages. Therefore, I believe we can abandon the widespread idea that northern Italian wh-in situ is of a different type compared to Asian wh-in situ, and rather start looking at this phenomenon in the new light of WH-TO-FOC. Before moving to the conclusions, note that Poletto \& Pollock (2019) presented an evolution of the remnant-IP movement theory whereby wh-in situ is derived exploiting both peripheries. However, despite the attractiveness of a theory that partially derives wh-in situ by making use of the LLP, I maintain that an exploitation of the low part of the HLP requires the stipulation of too big a typological gap between closely-related varieties, which should be avoided as much as possible.

\section{Conclusions}

Cross-linguistically, the low movement of both wh-elements and foci is a robust phenomenon that has been almost completely disregarded in the literature on Romance, with the notable exception of Kato's (2013) analysis of Brazilian Portuguese and a few mentions of the role played by Foc in the derivation of interrogatives (Belletti 2006, Manzini 2012, Badan \& Crocco 2021). Here, I have provided evidence of the existence of this peculiar low movement in Trevisan, a NID, and claimed that a reconsideration of the role of the Romance LLP is in order.

Theoretically, I have shown that the implementation of Q-particles in Romance is not an ad hoc strategy, but rather one that is empirically supported and results in a theory of northern Italian wh-in situ that is both cross-linguistically valid and diachronically justified. I have also suggested that this adaptation of Cable's (2010) Grammar of Q provides a more economical, less typologically distant explanation for Bellunese than the remnant-IP movement hypothesis, thus advocating a return to (an implementation of) Munaro's (1999) original theory.

In conclusion, the synchronic and diachronic facts presented in this article suggest that northern Italian and Asian wh-in situ are more similar than we might have thought and that all previous analyses of the former cannot be maintained. 


\section{References}

Aboh, Enoch. 2007. Leftward Focus versus Rightward Focus, the Kwa-Bantu Conspiracy. In N. C. Kula \& L. Marten (eds.) Bantu in Bloomsbury: Special Issue on Bantu Linguistics. SOAS Working Papers in Linguistics 15. SOAS University of London. 81-104. https://doi.org/10.21248/zaspil.43.2006.291

Aboh, Enoch \& Roland Pfau. 2011. What's a Wh-Word Got to Do with It? In P. Benincà \& N. Munaro (eds.) Mapping the Left Periphery. Oxford University Press. https://doi.org/10.1093/acprof:oso/9780199740376.003.0004

Aldridge, Edith. 2009. Short Wh-movement in Old Japanese. In S. Iwasaki, H. Hoji, P. Clancy \& S. Sohn (eds.) Japanese/Korean Linguistics 17. 549-563.

Aldridge, Edith. 2010. Clause-internal Wh-movement in Archaic Chinese. Journal of East Asian Linguistics 19 (1). Springer. 1-36. https://doi.org/10.1007/s10831-009-9054-z

Aoun, Joseph \& Yen-hui Audrey Li. 1993. Wh-elements in Situ: Syntax or LF? Linguistic Inquiry 24. 199-238.

Aoun, Joseph \& Yen-hui Audrey Li. 2003. Essays on the Representational and Derivational Nature of Grammar: The Diversity of Wh-Constructions. MIT Press. https://doi.org/10.1017/s0022226704212804

Badan, Linda. 2015. Left and right peripheries in Mandarin. Faits de langues. 46 (2). 23-38. https://doi.org/10.1163/19589514-046-01-900000004

Badan, Linda \& Claudia Crocco 2021. Italian wh-questions and the low periphery. Linguistics: An Interdisciplinary Journal of the Language Sciences. De Gruyter.

Badan, Linda \& Francesca Del Gobbo. 2010. On the syntax of topic and focus in Chinese. In P. Benincà \& N. Munaro (eds.) Mapping the left periphery. Oxford University Press. https://doi.org/10.1093/acprof:oso/9780199740376.003.0003

Baunaz, Lena. 2005. The Grammar of French Quantification. Studies in Natural Language and Linguistic Theory 83. Springer Netherlands.

Beck, Sigrid \& Shin-Sook Kim. 1997. On Wh- and Operator Scope in Korean. Journal of East Asian Linguistics 6. 339-384.

Belletti, Adriana \& Luigi Rizzi. 2017. On the Syntax and Pragmatics of Some Clause-Peripheral Positions. In J. Blochowiak et al. (eds.) Formal Models in the Study of Language. 33-48. https://doi.org/10.1007/978-3-319-48832-5_3

Belletti, Adriana. 2004. Aspects of the low IP area. In L. Rizzi (ed.) The Structure of IP and CP. The Cartography of Syntactic Structures. Oxford University Press.

Belletti, Adriana. 2006. Clefts and wh in situ: some notes. Paper presented at the Lisbon COST-Meeting. July 6-8, 2006. Ms.

Bianchi, Valentina. 2013. On 'focus movement' in Italian. In V. CamachoTaboada, Á. L. Jiménez Fernández, J. Martín-González \& M. ReyesTejedor (eds.) Information Structure and Agreement. Linguistik 
Aktuell/Linguistics Today 197. The John Benjamins Publishing Company. 193-216. https://doi.org/10.1075/la.197.07bia

Bianchi, Valentina \& Giuliano Bocci. 2012. Should I Stay or Should I Go? Optional Focus Movement in Italian. In C. Piñon (ed.) Empirical Issues in Syntax and Semantics 9. 1-18.

Biezma, María. 2018. Givenness and the difference between wh-fronted and whin-situ questions in Spanish. Romance Languages and Linguistic Theory: Selected papers for Going Romance 29. The John Benjamins Publishing Company. 21-39. https://doi.org/10.1075/rllt.13.03bie

Bocci, Giuliano, Valentina Bianchi \& Silvio Cruschina. (2020). Focus in whquestions. Evidence from Italian. Natural Language and Linguistic Theory. Springer. https://doi.org/10.1007/s11049-020-09483-x

Bonan, Caterina. 2017. Arguing against a one-fits-all derivation for Northern Italian Insituness. In J. Garzonio (ed.) Quaderni di lavoro ASIt 20. ISSN: 18282326. 49-76.

Bonan, Caterina. 2019. On clause-internally moved wh-phrases: wh-to-Foc, nominative clitics, and the theory of Northern Italian wh-in situ. PhD dissertation. Université de Genève. https://doi.org/10.13097/archive-ouverte/unige:119060

Bonan, Caterina. 2021. [in press] Romance interrogative syntax. Formal and typological dimensions of variation. Linguistik Aktuell/Linguistics Today 266. The John Benjamins Publishing Company. https://doi.org/10.1075/la.266

Bonan, Caterina. 2021b. The periphery of $v \mathrm{P}$ in the theory of wh-in situ. Ms in review.

Bonan, Caterina \& Ur Shlonsky. 2021. [accepted] 'Why' in situ in Northern Italian dialects: evidence from Trevisan. In G. Soare (ed.) Proceedings of the 2017 SLE meeting, University of Zürich.

Bošković, Želiko. 2014. Now I'm a Phase, Now I'm Not a Phase: On the Variability of Phases with Extraction and Ellipsis. Linguistic Inquiry 45. MIT Press. 27-89.

https://doi.org/10.1162/ling_a_00148

Boyd-Bowman, Peter. 1980. From Latin to Romance in Sound Charts. Georgetown University Press.

Cable, Seth. 2010. The Grammar of Q. Q-Particles, Wh-Movement, and PiedPiping. Oxford Studies in Comparative Syntax. Oxford University Press.

Cardinaletti, Anna. 2002. Against Optional and Null Clitics. Right Dislocation vs. Marginalization. Studia Linguistica 56. 29-57. https://doi.org/10.1111/1467-9582.00086

Cheng, Lisa Lai-Shen. 1991. On the Typology of Wh-questions. PhD Dissertation. MIT.

Cheng, Lisa Lai-Shen. 2003. Wh-in-situ. Glot International 7 (4). Blackwell Publishing. 103-109.

Cheng, Lisa Lai-Shen. 2009. Wh-in-situ, from the 1980s to Now. Language and Linguistics Compass 3 (3). 767-791. 
https://doi.org/10.1111/j.1749-818x.2009.00133.x

Cheng, Lisa Lai-Shen. \& Joseph Bayer. 2017. Wh-in-situ. In M. Everaert \& H. van Riemsdijk (eds.) The Blackwell Companion to Syntax.

Cheng, Lisa Lai-Shen \& Johan Rooryck. 2000. Licensing WH-in-situ. Syntax 3 (1). $1-19$.

https://doi.org/10.1111/1467-9612.00022

Cheung, Candice Chi-Hang. 2008. Wh-fronting in Chinese. PhD dissertation. University of Southern California.

Cheung, Candice Chi-Hang. 2014. Wh-fronting and the left periphery in Mandarin. Journal of East Asian Linguistics 23. 393-431. https://doi.org/10.1007/s10831-013-9112-4

Chomsky, Noam. 1995. The Minimalist Program. MIT Press.

Chomsky, Noam. 2001. Derivation by Phase. In M. Kenstowicz (ed.) Ken Hale: A Life in Language. MIT Press. 1-52.

Cinque, Guglielmo. 1999. Adverbs and Functional Heads: A Cross-Linguistic Perspective. Oxford Studies in Comparative Syntax. Oxford University Press. https://doi.org/10.1017/s0022226705243396

Cole, Peter. \& Gabriella Hermon. 1994. Is There LF Wh-Movement? Linguistic Inquiry 25 (2). MIT Press. 239-262.

Cole, Peter. \& Gabriella Hermon. 1998. The Typology of Wh-Movement: WhQuestions in Malay. Syntax 1. 221-258. https://doi.org/10.1111/1467-9612.00009

Cruschina, Silvio. 2012. Discourse-Related Features and Functional Projections. Oxford Comparative Studies in Syntax. Oxford University Press. https://doi.org/10.1093/acprof:oso/9780199759613.001.0001

Dadan, Marcin. 2019. Head Labeling Preference and Language Change. PhD dissertation. University of Connecticut.

Dauenhauer, Nora \& Richard Dauenhauer. 2000. Beginning Tlingit. Sealaska Heritage Foundation.

Dayal, Veneeta. 2017. Does Hindi-Urdu Have Feature-Driven Wh-Movement to Spec, $v$ P? Linguistic Inquiry 48 (1). MIT Press. 159-172. https://doi.org/10.1162/ling_a_00238

den Dikken, Marcel. 2003. On the morphosyntax of wh-movement. In C. Boeckx \& K. Grohmann (eds.) Multiple Wh-Fronting. John Benjamins. 77-98.

Déprez, Viviane, Kristen Syrett \& Shigeto Kawahara. 2012. Interfacing information and prosody. In I. France, S. Lusini \& A. Saab (eds.) French wh-in-situ questions. Romance Languages and Linguistic Theory 2010. The John Benjamins Publishing Company. 135-154. https://doi.org/10.1075/rllt.4.07dep

Déprez, Viviane, Kristen Syrett \& Shigeto Kawahara. 2013. The interaction of syntax, prosody, and discourse in licensing French wh-in-situ questions. Lingua 124. 4-19. https://doi.org/10.1016/j.lingua.2012.03.002

É. Kiss, Katalin. 1998. Identificational Focus versus Information Focus. Language 74 (2). 245-273. https://doi.org/10.1353/lan.1998.0211 
Etxepare, Ricardo \& Myriam Uribe-Etxebarria. 2005. In situ wh-phrases in Spanish: locality and quantification. Recherches Linguistiques de Vincennes 33. Presses Universitaires de Vincennes. 9-34. https://doi.org/10.4000/rlv.1238

Faure, Richard \& Katerina Palasis. 2021. Exclusivity! Wh-fronting is not optional wh-movement in Colloquial French. Natural Language and Linguistic Theory 39. 57-95. https://doi.org/10.1007/s11049-020-09476-w

Figueiredo Silva, Maria Cristina \& Grolla, Elaine. 2016. Some syntactic and pragmatic aspects of WH-in-situ in Brazilian Portuguese. In M. A. Kato \& F. Ordóñez (eds.) The Morphosyntax of Portuguese and Spanish in Latin America. Oxford Studies in Comparative Syntax. Oxford University Press. 259-285. https://doi.org/10.1093/acprof:oso/9780190465889.003.0011

Gao, Qian. 1994. Focus Criterion: Evidence from Chinese. Proceedings of the $6^{\text {th }}$ North American Conference on Chinese Linguistics, University of Southern California.

Gess, Randall. 1996. Optimality Theory in the Historical Phonology of French. $\mathrm{PhD}$ dissertation, University of Washington.

Giorgi, Alessandra 2016. Epistemic adverbs, the prosody-syntax interface and the theory of phases. Romance linguistics 2013: Selected papers from the 43rd Linguistic symposium on Romance languages. The John Benjamins Publishing Company. 99-117. https://doi.org/10.1075/rllt.9.06gio

Hagstrom, Paul Alan. 1998. Decomposing questions. PhD Dissertation. MIT.

Horvath, Julia. 1986. Focus in the theory of grammar and the syntax of Hungarian. Studies in Generative Grammar 24. De Gruyter Mouton. https://doi.org/10.1515/9783110849165

Huang, James Cheng-Teh \& Yen-Hui Audrey Li. 2009. The Syntax of Chinese. Cambridge Syntax Guides. Cambridge University Press. doi:10.1017/CBO9781139166935.

Huang, James Cheng-Teh. 1982. Logical Relations in Chinese and the Theory of Grammar. PhD dissertation. MIT.

Hyman, Larry. 2005. Focus Marking in Aghem: Syntax or Semantics? Paper presented at the

Conference on Focus in African Languages. ZAS Berlin.

Jayaseelan, Karattuparambil Achuthan. 1996. Question-word movement to focus and scrambling in Malayalam. Linguistic Analysis 26. 63-83.

Jin, Dawei. 2014. Contradiction, Wh-Questions and Complex Islands in Chinese. University of Pennsylvania Working Papers in Linguistics 21 (1). Proceedings from PLC 38.

Kahnemuyipour, Arsalan. 2001. On Wh-Questions in Persian. Canadian Journal of Linguistics/Revue Canadienne de Linguistique 46 (1/2). 41-51. https://doi.org/10.1017/s000841310001793x

Kaiser, Georg. \& Stefano Quaglia. 2015. In search of wh in-situ in Romance; an investigation in detective stories. In E. Brandner, A. Czypionka, C. Freitag, T. Constantin \& A. Trotzke (eds.) Charting the Landscape of Linguistics: On the Scope of Josef Bayer's Work. 92-103. 
Karimi, Simin \& Azita Hojatollah Taleghani. 2007. Wh-movement, interpretation, and optionality in Persian. In S. Karimi, V. Samiian \& W. Wilkins (eds.) Clausal and phrasal architecture: syntactic derivation and interpretation. Linguistik Aktuell/Linguistics Today 101. The John Benjamins Publishing Company. 167-187. https://doi.org/10.1075/la.101.09kar

Kato, Mary Aizawa. 2003. The interpretation and derivation of wh-in-situ constructions in Brazilian Portuguese. UniCamp. Ms.

Kato, Mary Aizawa. 2013. Deriving "wh-in-situ" through mouvement in Brazilian Portuguese. In V. Camacho-Taboada, Á. L. Jiménez Fernández, J. MartínGonzález \& M. Reyes-Tejedor (eds.) Information Structure and Agreement. Linguistics Today/Linguistik Aktuell 197. The John Benjamins Publishing Company. 175-192. https://doi.org/10.1075/la.197.06kat

Kayama, Yuhko. (2005) Acquisition of Wh-in-situ: The Case of L2 Japanese.

Kayne, Richard Stanley. 1994. The Antysymmetry of Syntax. Linguistic Inquiry Monographs. MIT Press.

Kayne, Richard Stanley. 1998. Overt vs Covert Movement. Syntax 1 (2). Wiley. 128-191.

https://doi.org/10.1111/1467-9612.00006

Kidway, Ayesha. 2000. XP-adjunction in Universal Grammar: Scrambling and binding in Hindi-Urdu. Oxford Studies in Comparative Syntax. Oxford University Press. https://doi.org/10.1353/lan.2005.0063

Kishimoto, Hideki. 2005. Wh-in-situ and movement in Sinhala questions. Natural Language \& Linguistic Theory 23 (1). 1-51. https://doi.org/10.1007/s11049-004-6574-0

Kotek, Hadas 2016. On the semantics of wh-questions. Proceedings of Sinn und Bedeutung ( $S u B$ ) 20, eds. Nadine Bade, Polina Berezovskaya and Anthea Scholler.

Kotek, Hadas \& Michael Yoshitaka Erlewine. 2016. Covert pied-piping in English multiple wh-questions. Linguistic Inquiry 47 (4). 669-693. MIT Press. https://doi.org/10.1162/ling_a_00226

Kuno, S. \& Robinson, J. J. 1972. Multiple Wh Questions. LI 3 (4). 463-487. MIT Press.

Ledgeway, Adam \& Alessandra Lombardi. 2005. Verb Movement, Adverbs and Clitic Positions in Romance. Probus 17. 79-113. https://doi.org/10.1515/prbs.2005.17.1.79

Li, Wang. 1962. Ancient Chinese [4 volumes].

Li, Yen-Hui Audrey. 1992. Indefinite Wh in Mandarin Chinese. Journal of East Asian Linguistics 1. 125-156. https://doi.org/10.1007/bf00130234

Lin, Jo-Wang. 1998. On existential polarity in wh-phrases in Chinese. Journal of East Asian Linguistics 7. 219-255.

Lin, Jo-Wang. 2004. Choice functions and scope of existential polarity in whphrases in Mandarin Chinese. Linguistics and Philosophy 27. 451-491. https://doi.org/10.1023/b:ling.0000024407.76999.f7 
Mahajan, Anoop Kumar. 1990. The A/A' Distinction and Movement Theory. PhD Dissertation. MIT.

Manetta, Emily. 2010. Wh expletives in Hindi-Urdu: The $v \mathrm{P}$ phase. Linguistic Inquiry 41 (1). MIT Press. 1-34. https://doi.org/10.1162/ling.2010.41.1.1

Manzini, Maria Rita \& Leonardo Maria Savoia. 2005. I dialetti italiani e romanci. Morfosintassi generativa I-III. Edizioni dell'Orso.

Manzini, Maria Rita \& Leonardo Maria Savoia. 2011. Wh-in situ and wh-doubling in Northern Italian varieties: Against remnant movement. Linguistic Analysis 37 (1 \& 2). 79-113.

Manzini, Maria Rita. 2014. Grammatical categories: Strong and weak pronouns in Romance. Lingua 150. Elsevier. 171-201. https://doi.org/10.1016/j.lingua.2014.07.001

Mathieu, Éric. 2009. Les questions en français: micro- et macro-variation. In Martineau F. et al. (eds.) Le français d'ici: études linguistiques et sociolinguistiques de la variation. GREF. https://doi.org/10.1353/utq.2011.0140

McCloskey, James. 2001. The morphosyntax of wh-extraction in Irish. Journal of Linguistics 37 (1). Cambridge University Press. 67-100. https://doi.org/10.1017/s0022226701008775

McCloskey, James. 2002. Resumption, Successive Cyclicity, and the Locality of Operations. In S. D. Epstein \& T. D. Seely (eds.) Derivation and Explanation in the Minimalist Program. Blackwell Publishers. 184-226. https://doi.org/10.1002/9780470755662.ch9

McDaniel, Dana. 1986. Conditions on Wh-Chains. PhD dissertation. City University of New York.

McDaniel, Dana. 1989. Partial and Multiple Wh-Movement. Natural Language and Linguistic Theory 7 (4). Kluwer Academic Publishers. 565-604. https://doi.org/10.1007/BF00205158

Miyagawa, Shigeru. 2001. The EPP, scrambling, and wh-in-situ. In Ken Hale: A Life in Language, M. Kenstowicz (ed.) MIT Press. 293-388. https://doi.org/10.7551/mitpress/4056.003.0012

Miyagawa, Shigeru. 2009. Why Agree? Why Move? Unifying Agreement-Based and Discourse-Configurational Languages. Linguistic Inquiry Monographs 54. MIT Press. https://doi.org/10.7551/mitpress/8116.001.0001

Munaro, Nicola, Cecilia Poletto \& Jean-Yves Pollock. 2001. Eppur si muove! On comparing French and Bellunese wh-movement. In P. Pica (ed.) Linguistic Variation Yearbook 1. The John Benjamins Publishing Company. 147-180. https://doi.org/10.1075/livy.1.07mun

Munaro, Nicola \& Cecilia Poletto. 2003. Sentential Particles and Clausal Typing in the Veneto Dialects. https://doi.org/10.21248/zaspil.35.2004.234

Munaro, Nicola. 1995. On nominal wh-phrases in some North-Eastern Italian dialects. Rivista di Grammatica Generativa 20. 69-110

Munaro, Nicola. 1999. Sintagmi interrogativi nei dialetti italiani settentrionali. Rivista di Grammatica Generativa. Monografie. Unipress. 
Pan, Victor Junnan. 2014. Wh-ex-situ in Mandarin Chinese: Mapping Between Information Structure and Split CP. Linguistic Analysis 39 (3 \& 4). 371413.

Paris, Marie-Claude. 1998. Focus Operators and Types of Predication in Mandarin. Cahiers de Linguistique Asie Orientale 27(2): 139-159. https://doi.org/10.3406/clao.1998.1531

Pesetsky, David. 2000. Phrasal Movement and its Kin. Linguistic Inquiry Monographs 37. MIT Press. https://doi.org/10.1017/s0022226702281980

Peyraube, Alain. 1997. On word order in Archaïc Chinese. Cahiers de Linguistique - Asie Orientale 26 (1). 3-20. https://doi.org/10.3406/clao.1997.1502

Pires, Acrisio \& Heather Lee Taylor. 2009. The Syntax of Wh-in-Situ and Common Ground. Proceedings from the Annual Meeting of the Chicago Linguistic Society 43 (2). 201-215.

Poletto, Cecilia. 2006. Parallel Phases: A study on the high and low left periphery of Old Italian. Phases of Interpretation 91. 261-294. https://doi.org/10.1515/9783110197723.4.261

Poletto, Cecilia \& Jean-Yves Pollock. 2000. On the Left Periphery of Some Romance Wh-Questions. University of Venice Working Papers in Linguistics 20 (2).

Poletto, Cecilia \& Jean-Yves Pollock. 2004. On wh-clitics and wh-doubling in French and some North Eastern Italian Dialects. Probus 16. 241-277. https://doi.org/10.1515/prbs.2004.16.2.241

Poletto, Cecilia \& Jean-Yves Pollock. 2015. Arguing for remnant movement in Romance. In G. Grewendorf (ed.) Remnant Movement. Mouton de Gruyter. https://doi.org/10.1515/9781614516330-006

Poletto, Cecilia \& Jean-Yves Pollock. 2019. Remnant Movement and Smuggling in Some Romance Interrogative Clauses. To appear in Smuggling in Syntax. Oxford University Press. https://doi.org/10.1093/oso/9780197509869.003.0010

Reglero, Laura. 2015. Wh-in-Situ Constructions: Syntax and/or Phonology? In J. Alderete et al. (eds.) Proceedings of the 24th West Coast Conference on Formal Linguistics. Cascadilla Proceedings Project. 334-342.

Rizzi, Luigi. \& Guglielmo Cinque. 2016. Functional Categories and Syntactic Theory. Annual Review of Linguistics. 139-163. https://doi.org/10.1146/annurev-linguistics-011415-040827

Rizzi, Luigi. 1996. Residual verb second and the Wh-Criterion. In A. Belletti \& L. Rizzi (eds.) Parameters and functional heads. Oxford University Press. 6390.

Rizzi, Luigi. 1997. The Fine Structure of the Left Periphery. In L. Haegeman (ed.) Elements of Grammar. Kluwer International Handbooks of Linguistics. Springer. 281-337. https://doi.org/10.1007/978-94-011-5420-8_7

Rizzi, Luigi. 2001. On the Position Int(errogative) in the Left Periphery of the Clause. In G. Cinque \& G. Salvi (eds.) Current Studies in Italian Syntax: Essays offered to Lorenzo Renzi. North Holland Linguistic Series. Linguistic Variations 59. 287-296. 
https://doi.org/10.1016/s0024-3841(01)00057-2

Rizzi, Luigi. 2006. On the Form of Chains: Criterial Positions and ECP Effects. In L. Cheng \& N. Corver (eds.) Wh-Movement: Moving On. MIT Press. 97133.

https://doi.org/10.7551/mitpress/7197.003.0010

Rizzi, Luigi. 2010. On Some Properties of Criterial Freezing. In E. Phoevos Panagiotidis (ed.) The Complementizer Phase: Subjects and Operators. Oxford Studies in Theoretical Linguistics. Oxford University Press. https://doi.org/10.1093/acprof:oso/9780199584352.003.0002

Rizzi, Luigi. 2018. Intervention effects in grammar and language acquisition. Probus 30 (2). 339-367.

https://doi.org/10.1515/probus-2018-0006

Roberts, Ian. 2007. A Deletion Analysis of Null Subjects: French as a Case Study. In A. Holmberg \& I. Roberts (eds.) Null Subjects: the structure of parametric variation. Cambridge University Press. https://doi.org/10.1017/cbo9780511770784.002

Roberts, Ian. 2010. Agreement and Head Movement. Clitics, Incorporation, and Defective Goals. Linguistic Inquiry Monographs 59. MIT Press. https://doi.org/10.1017/s0022226711000120

Rosemeyer, Malte. 2019. Brazilian Portuguese in-situ wh-interrogatives between rhetoric and change. Glossa: A Journal of General Linguistics 4 (1) 80. http://doi.org/10.5334/gigl.900

Roussou, Anna, Christos Vlachos \& Dimitris Papazachariou. 2014. In Situ, Ex Situ and (Non) Echo Questions. In N. Lavidas, T. Alexiou \& A.-M. Sougari (eds.) Major Trends in Theoretical and Applied Linguistics 1. De Gruyter Open Poland. 475-494. https://doi.org/10.2478/9788376560762.p317

Samek-Lodovici, Vieri. 2015. The Interaction of Focus, Givenness, and Prosody. A Study of Italian Clause Structure. Oxford Studies in Theoretical Linguistics. Oxford University Press. https://doi.org/10.1093/acprof:oso/9780198737926.001.0001

Shlonsky, Ur. 2012. Notes on wh in situ in French. In L. Brugè, A. Cardinaletti, G. Giusti, N. Munaro \& C. Poletto (eds.) Functional Heads. The Cartography of Syntactic Structures 7. Oxford University Press. 242-252. https://doi.org/10.1093/acprof:oso/9780199746736.001.0001

Shlonsky, Ur \& Gabriela Soare. 2011. Where's 'Why'? Linguistic Inquiry 42 (4). MIT Press. 651-669. https://doi.org/10.1162/ling_a_00064

Slade, Benjamin Martin. 2011. Formal and philological inquiries into the nature of interrogatives, indefinites, disjunction, and focus in Sinhala and other languages. $\mathrm{PhD}$ dissertation. University of Illinois at Urbana-Champaign.

Soh, Hooi Ling. 2005. Wh-in-Situ in Mandarin Chinese. Linguistic Inquiry 36 (1). MIT Press. 143-155. https://doi.org/10.1162/ling.2005.36.1.143

Stepanov, Arthur \& Wei-Tien Dylan Tsai. 2008. Cartography and licensing of whadjuncts: A crosslinguistic perspective. Natural Language and Linguistic Theory 26 (3). Springer. 589-638. https://doi.org/10.1007/s11049-008-9047-z 
Tang, Chih-Chen Jane (1988). Wh-topicalization in Chinese. Ms. Cornell University.

Torrego, Esther. 1984. On Inversion in Spanish and Some of its Effects. Linguistic Inquiry 15. MIT Press. 103-129.

Tsai, Wei-Tien Dylan. 1994. On Economizing the Theory of A-bar Dependencies. PhD Dissertation. MIT.

Turano, Giuseppina. 1998. Overt and covert Dependencies in Albanian. Studia Linguistica 52 (2).

https://doi.org/10.1111/1467-9582.00032

Ueno, Mieko. \& Kluender, Robert. 2003. On the processing of Japanese whquestions: Relating grammar and brain. In G. Garding \& M. Tsujimura (eds.) Proceedings of the Twenty-Second West Coast Conference on Formal Linguistics. Cascadilla Press. 491-504.

Uribe-Etxebarria, Myriam. 2002. In situ questions and masked movement. In P. Pica (ed.) Linguistic Variation Yearbook 2 (1). John Benjamins. 217-257 https://doi.org/10.1075/livy.2.09uri

van Urk, Coppe. \& Norvin Richards. 2015. Two Components of Long-Distance Extraction: Successive Cyclicity in Dinka. Linguistic Inquiry 46. MIT Press. 113-155. https://doi.org/10.1162/ling_a_00177

Vlachos, Christos \& Michalis Chiou. 2020. The syntax, semantics and pragmatics of 'optional' wh-in situ in Greek. Journal of Greek Linguistics 20 (1). Brill. $102-131$ https://doi.org/10.1163/15699846-02001001

Wahba, Wafaa Abdel-Faheem Batran. 1991. LF Movement in Iraqi Arabic. In C.T. J. Huang \& R. May (eds.) Logical Structure and Linguistic Structure. Studies in Linguistics and Philosophy 40. Springer. 253-276. https://doi.org/10.1007/978-94-011-3472-9_9

Watanabe, Akira. 2003. Loss of overt wh-movement in Old Japanese. In D. W. Lightfoot (ed.) Syntactic effects of morphological change. Oxford University Press. 179-195. https://doi.org/10.1093/acprof:oso/9780199250691.003.0010

Watters, John. 1979. Focus in Aghem: a study of its formal correlates and typology. In L. M. Hyman (ed.) Aghem Grammatical structure. With special reference to noun classes, tense-aspect and focus marking. Southern California Occasional Papers in Linguistics 7. 137-197.

Wei, Peichuan. 1999. Lun Xian-Qin Hanyu Yunfu de Weizhi [On the Position of Operators in Pre-Qin Chinese]. In Z. Mei, A. Peyaube \& C. Sun (eds.) Linguistic Essays in Honor of Mei Tsu-lin: Studies in Chinese Historical Syntax. Centre de Recherches Linguistiques sur l'Asie Orientale. 259-297.

Willis, David. 2000. On the distribution of resumptive pronouns and wh-trace in Welsh. Journal of Linguistics 36 (3). Cambridge University Press. 531-573. https://doi.org/10.1017/s0022226700008380

$\mathrm{Wu}$, Guo. 1999. A Unified Account of the Discourse Function of the Chinese Particle 'ne'. Macrolinguistics 3. 1-25.

$\mathrm{Wu}$, Jianxin. 1999. Syntax and semantics of quantification in Chinese. $\mathrm{PhD}$ Dissertation. University of Maryland at College Park. 
Yoshida, Keiko \& Tomoyuki Yoshida. 1996. Interrogative Feature Checking in Japanese and Korean. Language, Information and Computation (11). 257266. 